\title{
On the Mechanism of the $\gamma \rightarrow \beta$ Frequency Shift in Neuronal Oscillations Induced in Rat Hippocampal Slices by Tetanic Stimulation
}

\author{
Roger D. Traub, ${ }^{1}$ Miles A. Whittington, ${ }^{2}$ Eberhard H. Buhl, ${ }^{3}$ John G. R. Jefferys, ${ }^{1}$ and Howard J. Faulkner ${ }^{2}$ \\ ${ }^{1}$ Department of Physiology, University of Birmingham School of Medicine, Edgbaston, Birmingham B15 2TT, United \\ Kingdom, 2Department of Physiology, Imperial College of Medicine at St. Mary's, London W2 1PG. United Kingdom, and \\ 3Medical Research Council Anatomical Neuropharmacology Unit, Oxford University, Oxford OX1 3TH, United Kingdom
}

Tetanic stimulation of the CA1 region of rat hippocampal slices can induce $\gamma$ frequency population oscillations $(30-100 \mathrm{~Hz})$ after a latency of 50-150 msec that are synchronized to within 1-2 msec when simultaneous stimuli are delivered to two sites $2 \mathrm{~mm}$ or more apart. When tetanic stimuli, twice-threshold for eliciting $\gamma$ oscillations, are used, new phenomena occur. (1) After a period of $\gamma$, there is a switch to $\beta$ frequencies $(10-25 \mathrm{~Hz}$ ); (2) during the switch, pyramidal cell spike afterhyperpolarizations (AHPs) increase and rhythmic EPSPs occur in pyramidal cells; and (3) after an episode of single-site, twice-thresholdinduced $\gamma / \beta$ oscillations, simultaneous two-site threshold stimuli induce $\gamma$ oscillations that are locally synchronized, but no longer are capable of long-range synchrony. We studied the cellular mechanisms of the $\gamma / \beta$ switch with electrophysiological techniques and computer simulations. Our model predicts that the observed increases in both pyramidal cell AHPs and in pyramidal/pyramidal cell EPSPs are necessary and sufficient for the $\beta$ switch to occur. Firing patterns generated by the model, both for pyramidal cells and for interneurons, resemble experimental records. A one-site twice-threshold stimulus might lead to an inability of the two sites to synchronize at $\gamma$ frequencies, after subsequent two-site stimulation, via this mechanism. If depression is induced at synapses coupling pyramidal cells at one site to interneurons at the other site, then two-site stimulation cannot produce interneuron doublets; hence, as shown previously, the two sites will be unable to synchronize. This mechanism works in simulations, and we provide experimental evidence that synaptic depression and loss of doublets occur after a sufficiently strong local tetanus to one site. We suggest that long-range excitatory connections onto interneurons determine whether different pyramidal cell "assemblies" can synchronize at $\gamma$ frequencies, whereas excitatory connections onto pyramidal cells determine whether such assemblies can synchronize at $\beta$ frequencies.

Key words: synaptic plasticity; memory; interneurons; $40 \mathrm{~Hz}$ oscillation; hippocampus; EEG $\gamma$ oscillations $(>25 \mathrm{~Hz})$ have been found in vivo in various limbic, olfactory, and neocortical structures, occurring spontaneously, in response to sensory stimulation, in association with motor performance, or after electrical stimulation of certain brainstem and diencephalic nuclei [for review, see Gray (1994) and Singer and Gray (1995); see also Ribary et al. (1991), Murthy and Fetz (1992), Barth and MacDonald (1996), Steriade and Amzica (1996)]. It is possible that $\gamma$ oscillations play an important role in information processing, either by providing a means for "coincidence detection" (König et al., 1996) or by other cellular mechanisms. $\beta$ oscillations $(10-25 \mathrm{~Hz})$ have also been recognized in cortical structures (Leung, 1992), for example, during a sensorimotor task (Roelfsema et al., 1997), but also in humans taking sedative drugs (Glaze, 1990). A shift from $\gamma$ to $\beta$ frequencies has been observed in human neocortical event-related potentials (Pantev, 1995, his Fig. 5). The functional significance of $\beta$ frequency oscillations is unknown, and the mechanisms of different sorts of $\beta$ oscillations may not be identical.

\footnotetext{
Received Aug. 31, 1998; revised Oct. 28, 1998; accepted Nov. 13, 1998.

This work was supported by the Wellcome Trust, the Medical Research Council (United Kingdom), and the Human Frontier Science Program. R.D.T. is a Wellcome Principal Research Fellow. We acknowledge helpful discussions with Nancy Kopell, Bard Ermentrout, Hannah Monyer, and Andrea Bibbig.

Correspondence should be addressed to R. D. Traub, Division of Neuroscience, University of Birmingham School of Medicine, Edgbaston, Birmingham B15 2TT, UK.

Copyright (ㄷ) 1999 Society for Neuroscience $\quad 0270-6474 / 99 / 191088-18 \$ 05.00 / 0$
}

The evidence supporting a functional role for $\gamma$ oscillations is intriguing, yet also circumstantial. Better understanding of the cellular mechanisms of both $\gamma$ and $\beta$ oscillations may prove important, insofar as it could lead to means of manipulating the phenomenon in transgenic animals and observing the consequences. An analogous program has been initiated with NMDA receptor-mediated long-term potentiation (LTP) (McHugh et al., 1996).

As in the study of epileptogenesis, brain slices have proven to be useful in elucidating the cellular mechanisms of $\gamma$-frequency neuronal oscillations, although it remains to be proven that the mechanisms operative in vitro are the same as those operative in vivo. Briefly, we know that what happens in the CA1 region of rat hippocampal slices is as follows.

(1) Pharmacologically isolated networks of interneurons, presumably including basket cells, oscillate synchronously during tonic activation of interneuronal metabotropic receptors, the frequency and synchrony being regulated by interneuron $\rightarrow$ interneuron $\mathrm{GABA}_{\mathrm{A}}$ receptor-mediated synaptic connections (Whittington et al., 1995; Traub et al., 1996a). This type of synchrony does not extend over long distances, and $1.2 \mathrm{~mm}$ is an upper bound on the distance over which "interneuron network $\gamma$ " synchrony can extend in the rat CA1 region in vitro (Whittington et al., 1997a).

(2) Tetanic stimulation can elicit, after a delay of tens of milliseconds or more, a $\gamma$ oscillation extending $\sim 400 \mu \mathrm{m}$ from the 
stimulus (Colling et al., 1998). This "pyramidal/interneuron network $\gamma$ " (PING) is associated with population spikes; in addition, interneurons and pyramidal cells fire in phase, to within a few milliseconds. During PING, both cell types experience a long (hundreds of milliseconds or more) and large depolarization, mediated - at least in pyramidal cells-mainly by metabotropic glutamate receptors (Whittington et al., 1997a). The $\gamma$ oscillation is not time-locked to the stimulation.

(3) PING is capable of synchronizing to within 1 or $2 \mathrm{msec}$, over distances up to $4.5 \mathrm{~mm}$, when two sites are tetanically stimulated together. This occurs despite an estimated pyramidal cell axon conduction velocity of $0.5 \mathrm{~m} / \mathrm{sec}$ (hence conduction time for $4.5 \mathrm{~mm}=9 \mathrm{msec}$ ), and despite the fact that basket cell axons extend only $\sim 500 \mu \mathrm{m}$ in either direction from the cell body (Buhl et al., 1994a). After two-site stimulation, but not after one-site stimulation, interneurons often fire in spike doublets, with intradoublet intervals of $\sim 5 \mathrm{msec}$.

(4) Long-range synchrony of PING actually requires the occurrence of doublets in network simulations, the latter indicating that the second spike of the doublet, but not the first, is inducedvia AMPA receptors-by the synchronized pyramidal cell spike (Traub et al., 1996b; Whittington et al., 1998). AMPA receptor blockade eliminates long-range synchrony of PING, consistent with this prediction (Whittington et al., 1997a). The mechanisms by which interneuron doublets favor long-range synchrony have been analyzed theoretically by Ermentrout and Kopell (1998). The fact that two-site stimulation is necessary for interneuron doublets to occur suggests that long-range pyramidal cell $\rightarrow$ interneuron connections contribute critically to the generation of the interneuron doublets.

(5) When PING is evoked by an especially strong tetanic stimulus (twice-threshold intensity, designated $2 \times \mathrm{T}$, compared with threshold stimuli, designated $1 \times \mathrm{T}$ ), the $\gamma$ oscillation is followed by a relatively abrupt transition to a period of synchronized $\beta$ oscillation (10-25 Hz); here, "threshold" means "threshold for evoking the $\gamma$ oscillation." This occurs with either one-site or two-site stimulation, and in the latter case the $\beta$ is synchronized between the two sites. During $\beta$, a $\gamma$ rhythm continues in the interneurons, detectable as a ripple in the field potential and as $\gamma$-frequency IPSPs in pyramidal cells (Whittington et al., 1997b).

(6) During the $\gamma \rightarrow \beta$ transition in vitro, two events are notable in pyramidal cells: a return toward normal of fast-spike afterhyperpolarizations (AHPs) (which are largely blocked during $\gamma$ itself, presumably because of the action of metabotropic glutamate receptors), and the development of $\beta$-frequency, AMPA receptor-dependent EPSPs, which can reach $>5 \mathrm{mV}$ in amplitude. During $\beta$ itself, pyramidal cells sometimes fire spike doublets, and population spike doublets also can occur, a phenomenon that is rare during $\gamma$ oscillations in the CA1 region (Whittington et al., 1997b); population spike doublets can occur, however, during $\gamma$ oscillations in the subiculum (Stanford et al., 1998).

(7) A single administration of $2 \times \mathrm{T}$ stimulation produces longlasting changes at synaptic and network levels. For a period of hours, a subsequent $1 \times \mathrm{T}$ stimulation leads to rhythmic EPSPs in pyramidal cells, as well as to a $\beta$ oscillation after the initial $\gamma$ oscillation. If the $2 \times \mathrm{T}$ stimulation is given to both sites simultaneously, subsequent $1 \times \mathrm{T}$ stimulation (simultaneously to both sites) leads to $\gamma$ followed by $\beta$ at the two sites, with both oscillations synchronized between the two sites. Most remarkably, if a single administration of $2 \times \mathrm{T}$ stimulation is given to one site only, subsequent $1 \times \mathrm{T}$ stimulation at the two sites leads to $\gamma$ oscillations that no longer are capable of synchronizing together (Whittington et al., 1997b).

The aims of the present study are these: (1) to develop a detailed network model that replicates the known physiology of in vitro $\gamma$ oscillations, including interneuron doublets (the model should contain about as many neurons as in the experimental preparation and also contain different physiological/anatomical types of interneurons); (2) to demonstrate the predictive power of this model, by comparing the effects of blocking pyramidal cell $\rightarrow$ interneuron connections at one site, in model and experiment [the latter performed with joro spider toxin, a blocker of certain interneuron AMPA receptors (Iino et al., 1996)]; (3) to show in the model that the development of EPSPs and simultaneous increases in pyramidal cell spike AHPs are sufficient to account for the abrupt $\gamma \rightarrow \beta$ frequency transition (this idea was tested experimentally by blocking EPSPs, using pressure ejection of NBQX); and (4) to offer a hypothesis about why one-site $2 \times \mathrm{T}$ stimulation prevents future synchronization of $\gamma$ oscillations and to present experimental evidence that supports this hypothesis.

Our data will suggest a more general hypothesis concerning a role for oscillating neuronal assemblies in memory.

\section{MATERIALS AND METHODS}

\section{Experimental methods}

Transverse dorsal CA1 hippocampal slices $400-450 \mu \mathrm{m}$ thick were prepared from brains of 24 Sprague Dawley rats $(200-250 \mathrm{gm})$ that were killed by cervical dislocation followed by decapitation. Slices were maintained at $34-35^{\circ}$ at the interface between warm, wetted $95 \% \mathrm{O}_{2}-5 \% \mathrm{CO}_{2}$ and artificial CSF (ACSF) containing (in $\mathrm{mM}$ ): $\mathrm{NaCl} \mathrm{135,} \mathrm{KCl} \mathrm{3}$, $\mathrm{NaHCO}_{3} 16, \mathrm{NaH}_{2} \mathrm{PO}_{4} 1.25, \mathrm{CaCl}_{2} 1.5-2, \mathrm{MgCl}_{2}$ 0.8, D-glucose 10 .

To evoke oscillations, tetanic stimuli were delivered to stratum oriens at either of two sites (CA1a and CA1c; separation, 1.5-3 mm) or to both sites together. Each stimulus consisted of 20 pulses, $50 \mu \mathrm{sec}$ duration, at $100 \mathrm{~Hz}$. In each slice, the stimulus voltage was adjusted to be either threshold for evoking an oscillation $(1 \times \mathrm{T}$; value, 4-12 V) or twicethreshold $(2 \times \mathrm{T})$. Four different combinations of sites and stimuli were used: (1) $1 \times \mathrm{T}$ to one site; (2) $1 \times \mathrm{T}$ to both sites; (3) $2 \times \mathrm{T}$ to one site; and (4) $2 \times \mathrm{T}$ to both sites. In the same slice, at different times, one or another combination could be used, but we did not apply $1 \times \mathrm{T}$ stimulation at one site simultaneously with $2 \times \mathrm{T}$ stimulation at the other site. Extracellular field potentials were recorded at the two sites in stratum pyramidale with glass microelectrodes filled with $2 \mathrm{M} \mathrm{NaCl}(1-5 \mathrm{M} \Omega)$.

Intracellular recordings were taken from presumed pyramidal cells and interneurons in stratum pyramidale, distinguished by physiological criteria as described in Whittington et al. (1997a). Glass micropipettes were filled with $2 \mathrm{M}$ potassium acetate or methylsulfate (30-65 M $\Omega$ ). Recordings were digitized and analyzed using a CED analog/digital converter and associated software, including Spike2 (Cambridge, Electronic Design, Cambridge, UK).

In some experiments, drugs were puffed (pressure ejected) onto the tissue, using a glass micropipette with the tip broken $(100-500 \mathrm{k} \Omega$ ) and a pressure of $60 \mathrm{psi}$ for $50-150 \mathrm{msec}$. Drugs were dissolved in ACSF, including $20 \mu \mathrm{M}$ NBQX (Tocris) and $0.1 \mu \mathrm{M}$ joro spider toxin (RBI, Natick, MA; Sigma, St. Louis, MO). NBQX was puffed onto stratum oriens at a position approximately midway between the two stimulation sites. Joro toxin was puffed onto stratum pyramidale near one stimulation site.

\section{Simulation methods}

General comments on modeling large neuronal populations. The experimental observations in this study are not readily distilled into a single number, such as a relaxation time constant or a reversal potential. Rather, they consist of firing patterns generated by a large population of neurons. How, then, can one compare simulation results with experiments? This is a familiar issue in the physics of many interacting elements (phase transitions, turbulence). We are likewise seeking to replicate and understand the behavior of a complex system. Our approach involves three elements. 
(1) Model neurons should fire singlets, doublets, or bursts in situations in which corresponding real neurons do. The frequency of firing of pyramidal neurons and of interneurons should agree with the experiment. These features are what we shall mean by "firing patterns." In the future, when there is a deeper understanding of the oscillations, more subtle characteristics of the data may become amenable to analysis.

(2) When simulation traces differ from experimental ones in some detail, as in the shape of an afterpotential, the reason should be explicable, and one should be able to show that this difference is not critical when it comes to determining firing patterns. We cannot claim to reproduce every single aspect of the experimental recordings, so that simulation and experimental data are indistinguishable. To show that some features of the simulation data are not critical for determining firing patterns, it is helpful to construct a "reduced" model (although this remains to be accomplished for $\beta$ oscillations). For example, the existence of interneuron doublets and their importance for long-range $\gamma$ synchrony was predicted with a model using multicompartment neurons and a deterministic (and not very realistic) connection topology (Traub et al., 1996b). After experiments showed that interneuron doublets actually existed and were important in two-site synchronization (Traub et al., 1996b; Whittington et al., 1997a), Ermentrout and Kopell (1998) captured the essential physics of doublets in a model with only four single-compartment neurons. In this way, Ermentrout and Kopell (1998) highlighted the essential features of the system (the axon conduction delay between the sites, the precision and strength of synaptic excitation of interneurons), and one could learn also which features are not essential (e.g., the exact shape of the synaptic potentials), at least those that are not critical for this problem. In a similar way, simplified models exist for related phenomena, including interneuron network $\gamma$ (Wang and Buzsáki, 1996; White et al., 1998); analysis of such models provides clues about which parameters in the system are most critical for shaping the oscillation.

(3) The model must be predictive. The predictions can take several forms. (1) If the model is adjusted in some way to replicate the firing patterns of one sort of cell (e.g., pyramidal cells), then the firing patterns of the other sort of cells (e.g., interneurons) should be appropriate (see Figs. 4, 5). (2) A change in an identified parameter (e.g., the AMPA receptor-mediated conductance on a population of interneurons) should lead to a defined change (or lack of change) in firing patterns (see Fig. 3). (3) Conversely, a known change in firing pattern may imply a change in some particular parameter (see Figs. 10, 11). All of these types of prediction are experimentally testable.

This general approach has been used to study not only $\gamma$ oscillations in vitro, including the effects of anesthetic agents (Whittington et al., 1998), but also in vitro epileptogenesis (Traub et al., 1993, 1995).

Overall model structure. The model contained 3072 pyramidal cells (arranged in a $96 \times 32$ array), and 384 inhibitory cells, arranged in four rows, each containing 96 interneurons. The first of these rows consisted of "basket cells," the second of "axo-axonic cells," the third of "bistratified cells" (Halasy et al., 1996), and the fourth of "oriens/lacunosummoleculare (o/lm) cells" (Sik et al., 1995). The row-dimension (96 cells) is taken to represent a length along CA1 stratum pyramidale of $1.92 \mathrm{~mm}$. Pyramidal cell axons are allowed to contact cells anywhere in the array, but interneurons can contact only cells within some specified distance of the cell body (Fig. 1; see also below).

Intrinsic cell properties. For pyramidal cells, we began with a multicompartment CA3 pyramidal cell model (Traub et al., 1994). This model is a refinement of an earlier model based, in part, on voltage-clamp data (Traub et al., 1991). The soma-dendritic membrane contains the following active conductances: fast $g_{\mathrm{Na}}$, a single type of high-threshold noninactivating $g_{\mathrm{Ca}}$, a "delayed rectifier" $g_{\mathrm{K}}$, a transient "A" type of $g_{\mathrm{K}}$, a slow $\mathrm{Ca}^{2+}$-dependent $g_{\mathrm{K}(\mathrm{AHP})}$, and the faster voltage- and $\mathrm{Ca}^{2+}$-dependent $g_{\mathrm{K}(\mathrm{C})}$. Other conductances were not simulated: persistent $g_{\mathrm{Na}}$ and several types of $g_{\mathrm{Ca}}$ and $g_{\mathrm{K}}$, including the $\mathrm{M}$ conductance. This single-cell model can generate intrinsic bursts in response to current pulses or sustained dendritic currents and the transition from low-frequency bursting to higher frequency single spikes as the soma is depolarized. It does not always accurately reproduce spike afterpotentials, probably because of the incomplete repertoire of conductances. $g_{\mathrm{Ca}}$ density was multiplied by 0.5 to reduce the tendency to intrinsic bursting. In addition, $g_{\mathrm{K}(\mathrm{AHP})}$ density was reduced to $25 \%$ of its usual value during the $\gamma$ oscillation [simulating one effect of metabotropic glutamate receptors, which are known to be activated during tetanically induced $\gamma$ activity (Whittington et al., 1997a)], but this density returned to its usual value during the $\beta$ oscillation. This is in accordance with experimental observations on the

\section{pyramidal cells}

96 cells $=1.92 \mathrm{~mm}$

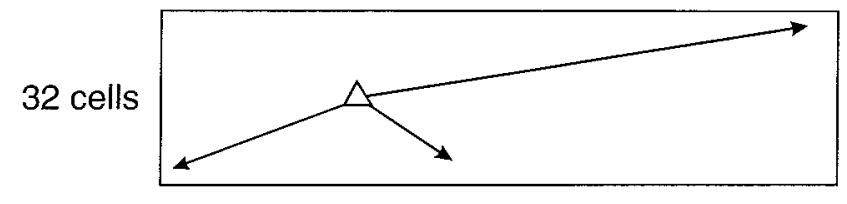

\section{interneurons}

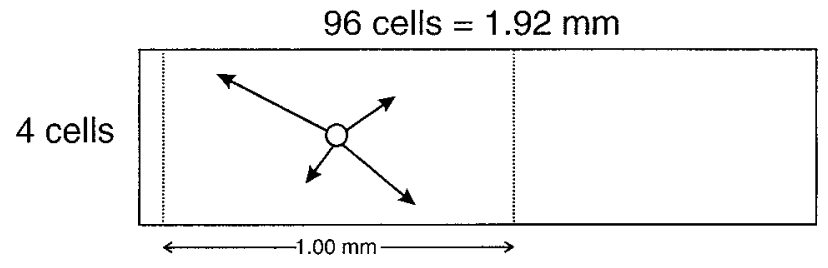

Figure 1. Structure of CA1 network model. The model consists of two interconnected arrays. The pyramidal cells (e-cells, top) are arranged in a $96 \times 32$ array, representing $1.92 \mathrm{~mm}$ along the long axis. Pyramidal cells contact other cells (pyramidal cells and interneurons) with probability that is independent of distance. The four types of interneurons (i-cells, bottom - -axo-axonic cells, basket cells, bistratified cells, and o/lm cellsare laid out in four lines of 96 interneurons each, one line for each type of interneuron. Interneurons contact other cells (either pyramidal cells or interneurons, except that axo-axonic cells do not contact interneurons), with probability that is uniformly random but subject to a constraint: presynaptic and postsynaptic cells must lie within $500 \mu \mathrm{m}$ of each other along the long axis.

recovery of fast-spike AHPs during the $\gamma / \beta$ transition (Whittington et al., 1997b), together with our presumption that slower AHPs recover as well. Recovery of fast-spike AHPs may result from a wearing off of the metabotropic glutamate receptor-mediated suppression of $I_{\mathrm{M}}$ (Charpak et al., 1990), or some other relatively fast $\mathrm{K}$ current, but metabotropic glutamate receptors also suppress $I_{\mathrm{K}(\mathrm{AHP})}$ (Charpak and Gähwiler, 1991), and this conductance would be expected to recover as well. (Note that we cannot simulate time-dependent changes in $g_{\mathrm{K}(\mathrm{M})}$ because this conductance is not included in the single-cell model, but fast AHPs should not significantly influence the $\beta$ oscillation, whose frequency is $10-25 \mathrm{~Hz}$ (period $40-100 \mathrm{msec}$ ). Slow AHPs, on the other hand, could well influence the $\beta$ oscillation by causing pyramidal cells to "skip beats" of the underlying $\gamma$ activity that persists during $\beta$; see below).

For interneurons, we began with the multicompartment model of Traub and Miles (1995), but we multiplied dendritic $g_{\mathrm{Na}}$ and $g_{\mathrm{K}}$ densities by 0.1 to allow for the low probability in CA1 of a single pyramidal cell spike causing an interneuron spike. In our simulations, the different sorts of interneurons had identical intrinsic properties, although their connectivity patterns and postsynaptic actions were different. We judged that insufficient data exist to justify distinguishable models of the various interneuron intrinsic properties and that the additional complexity was not justified for this stage of the model.

Both pyramidal cells and interneurons were excited with a constant or slowly varying excitatory synaptic conductance, intended to represent cellular excitation mediated by metabotropic receptors (Guérineau et al., 1995; Whittington et al., 1997a). In the model, this conductance had a reversal potential of $60 \mathrm{mV}$ positive to resting potential. For pyramidal cells, the total conductance was $55-60 \mathrm{nS}$ in some cases and $60-62 \mathrm{nS}$ in other cases. The conductance was chosen to be large enough so that the cells would fire on all or almost all $\gamma$ waves, as observed experimentally (Whittington et al., 1997a). The conductance was spread over the distal basilar dendrites and the apical dendrites [levels 1 and 5-11 in Traub et al. (1994)]. For interneurons, the total "driving" conductance was 10.010.2 nS, distributed over levels 3-5 and 9-11 (Traub and Miles, 1995, their Fig. 1). Again, this conductance was chosen to be large enough so that the interneurons would fire on each $\gamma$ wave.

Synaptic connectivity. Pyramidal cells could contact other neurons (either other pyramidal cells or interneurons) with a probability that was independent of location of either presynaptic or postsynaptic cell. This 
rule did not take into account the known anatomical asymmetry of CA1 pyramidal cell connections, when axons running toward the subiculum are compared with axons running toward CA2 (Tamamaki and Nojyo, 1990). (The anatomical asymmetry has so far not been shown to have physiological consequences for two-site tetanically evoked oscillations, in that systematic differences have not been noted between stimulating one end of CA1 vis-á-vis the other.) In contrast to pyramidal cells, interneurons could only contact other cells (either pyramidal cells or interneurons) that were within 25 cell diameters $(500 \mu \mathrm{m})$ of the presynaptic neuron, measuring along the long axis of the model array and ignoring the short axis. Within this "allowed region" for contacts, all connections had equal probability. The connectivity patterns of the different sorts of interneurons were identical, in a statistical sense. The latter two details of interneuron connectivity do not accord precisely with known anatomy, but our scheme does capture the relative spatial localization of interneuron synaptic outputs vis-á-vis pyramidal cell outputs.

Each pyramidal cell received synaptic input from 30 other pyramidal cells. Connections from one pyramidal cell to another were made to a single compartment in the basilar dendrites of the postsynaptic cell (Deuchars and Thomson, 1996); in reference to Traub et al. (1994), allowed contact sites were in levels 2 and 3 . The mean connection probability, $30 / 3072=0.98 \%$, is similar to the connection probability $(9 / 989=0.91 \%)$ estimated by Deuchars and Thomson (1996).

Each interneuron received synaptic input from 150 pyramidal cells. The contact sites were single compartments (Buhl et al., 1994a) in levels 1, 2, and 6-8 (Traub and Miles, 1995).

Each pyramidal cell received synaptic input from a total of 80 interneurons, 20 of each type [i.e., basket (Buhl et al., 1994a), axo-axonic (Buhl et al., 1994b), bistratified, o/lm]. Basket cells contacted the perisomatic region (levels 3-5), axo-axonic cells contacted the axon initial segment, bistratified cells contacted the middle and distal basilar dendrites (levels 1 and 2) and the middle apical dendrites (levels 6-9), and $\mathrm{o} / \mathrm{lm}$ cells contacted the distal apical dendrites (levels 10-11). Except for axo-axonic cells, the synaptic contacts were spread over all of the compartments in the respective levels.

Each interneuron received synaptic input from a total of 60 interneurons, 20 of each type, except for axo-axonic cells, which do not appear to contact other interneurons (Buhl et al., 1994b). Interneuron contacts took place on single compartments in the proximal dendrites, levels 3 and 5.

Synaptic actions. Only AMPA and $\mathrm{GABA}_{\mathrm{A}}$ receptor-mediated actions were simulated for connections between neurons. AMPA receptormediated conductances had a reversal potential $60 \mathrm{mV}$ positive to resting potential, and $\mathrm{GABA}_{\mathrm{A}}$ receptor-mediated conductances had a reversal potential $-15 \mathrm{mV}$ relative to resting potential. The time course of the unitary synaptic conductances (in $\mathrm{nS}$ ) were as follows: (1) pyramidal cell $\rightarrow$ pyramidal cell: $g \times t \times e^{(-\mathrm{t} / 2)}, g$ ranging from 0.0 to 3.45 (and $t$ in msec); (2) pyramidal cell $\rightarrow$ interneuron: $2 \times t \times e^{-\mathrm{t}}$ (this scaling constant of 2 allows the interneuron to develop doublets when enough presynaptic neurons are firing synchronously); (3) axo-axonic cell or basket cell $\rightarrow$ pyramidal cell: jump to $1.5 \mathrm{nS}$ over 1 time step, then exponential decay with time constant $10 \mathrm{msec}$ (Traub et al., 1996a); (4) bistratified cell or o/lm cell $\rightarrow$ pyramidal cell: jump to $1.5 \mathrm{nS}$ over 1 time step, then exponential decay with time constant 50 msec (Pearce, 1993); (5) basket cell $\rightarrow$ interneuron: jump to $2.0 \mathrm{nS}$ over 1 time step, then exponential decay with time constant $10 \mathrm{msec}$; and (6) bistratified cell or $\mathrm{o} / \mathrm{lm}$ cell $\rightarrow$ interneuron: jump to $0.2 \mathrm{nS}$ over 1 time step, then exponential decay with time constant 50 msec.

When several presynaptic cells fire, and these presynaptic cells contact the same compartment of the postsynaptic cell, then the resulting conductances are simply added together. There are saturation effects (in place for the sake of numerical stability): $\mathrm{GABA}_{\mathrm{A}}$ conductances cannot exceed $8 \mathrm{nS} /$ compartment on interneurons; AMPA conductances cannot exceed $8 \mathrm{nS} /$ compartment on pyramidal cells or $5 \mathrm{nS} /$ compartment on interneurons. We did not simulate time-dependent synaptic depression or facilitation.

Axon conduction velocity was $0.5 \mathrm{~m} / \mathrm{sec}$ for pyramidal cell axons (Colling et al., 1998) and $0.2 \mathrm{~m} / \mathrm{sec}$ for interneuron axons (Salin and Prince, 1996).

Noise in the system was simulated by having random ectopic spikes, originating in axons, with Poisson statistics and independently in different cells: averaging 1 ectopic spike per $10 \mathrm{sec}$ in pyramidal cells and 1 per $5 \mathrm{sec}$ in interneurons. These ectopic spikes propagate both antidromically and orthodromically to cause spontaneous synaptic potentials.
The program saved the somatic potential of selected pyramidal cells and interneurons and local average potentials (of 224 pyramidal cells or of 28 interneurons) at two sites, one at either end of the array (locations 5 and 91 along the long axis of the array).

Simulations were run for $1.5-2 \mathrm{sec}$ of "neuronal" time. Timedependent parameter changes, such as for EPSC amplitude or $g_{\mathrm{K}(\mathrm{AHP})}$ amplitude, took place over an interval in the middle of this time period. Neuronal activity is illustrated either for steady-state activity at the end of a run or for a time period spanning the interval of parameter changes, i.e., the interval over which the $\gamma / \beta$ transition takes place. Autocorrelations and cross-correlations were computed for intervals of at least 200 msec for $\gamma$ activity and $800 \mathrm{msec}$ for $\beta$ activity.

The code was written in FORTRAN with extra instructions for a parallel supercomputer, an IBM SP2 with 12 nodes. The approach to adapting a network algorithm to a parallel machine is described in Traub et al. (1995). The pseudo-random number generator used was part of an IBM software package, ESSL. The differential equations were integrated using a second-order Taylor series method [described in Traub and Miles (1991)], with a fixed integration step, $2.5 \mu \mathrm{sec}$ for pyramidal cells (Traub et al., 1994) and $1.25 \mu \mathrm{sec}$ for interneurons (Traub and Miles, 1995). In the original studies of single cells, a range of integration steps was tried, and the values used here were shown to yield stable results. Simulations took $\sim 1 \mathrm{hr}$ to run per $100 \mathrm{msec}$. (For details about the code, contact r.d.traub@bham.ac.uk.)

\section{RESULTS}

\section{Validation of network model}

\section{Simulation of $\gamma$ oscillations evoked by one- and two-site stimulation}

Before using the network model to study $\beta$ oscillations, it was necessary to show that it could replicate the basic physiology of $\gamma$ oscillations. First, it was shown by tonically exciting the interneurons alone and by disconnecting the pyramidal cells that the interneuron subnetwork would generate $\gamma$-frequency oscillations that were locally synchronized but could not synchronize to within $1 \mathrm{msec}$ across the $1.92 \mathrm{~mm}$ extent of the array (data not shown). This result is in agreement with previous experimental and simulation results (Whittington et al., 1997a). In part, this result implies that with the parameter choices used, the isolated interneuron subnetwork's behavior is dominated by IPSCs whose $\tau_{\mathrm{GABA}(\mathrm{A})}$ is $10 \mathrm{msec}$, rather than the longer-duration IPSCs induced by the dendrite-contacting interneurons.

We next stimulated pyramidal cells and interneurons simultaneously, with tonic excitatory conductances, either in one-half of the array (to simulate one-site stimulation) or in the whole array (to simulate two-site stimulation) (Fig. 2). The following experimental features (Traub et al., 1996a,b; Whittington et al., 1997a) of tetanically evoked $\gamma$ oscillations were thereby replicated. (1) Both pyramidal cells and interneurons fired at $\gamma$ frequencies, gated by $\mathrm{GABA}_{\mathrm{A}}$ IPSPs; (2) interneurons fired in doublets after two-site stimulation but not after one-site stimulation; (3) there was synchrony both locally and across the array (phase lag $1 \mathrm{msec}$ for two-site stimulation), the latter a consequence of interneuron doublet firing; (4) pyramidal cells fired approximately in phase with interneuron singlets during one-site stimulation (mean lag from pyramidal cell to interneuron, $1.3 \mathrm{msec}$ ), and with the first spike of the interneuron doublet during two-site stimulation (mean lag from pyramidal cell to interneuron $2.8 \mathrm{msec}$ ); and (5) the oscillation frequency was faster during one-site stimulation $(62 \mathrm{~Hz})$ than during two-site stimulation $(41 \mathrm{~Hz})$, again, a consequence of interneuron doublet firing during the latter case.

These features have been replicated in the previously used "chain" model of five cell groups in a row (Traub et al., 1996a,b; 
A

2-site stimulation

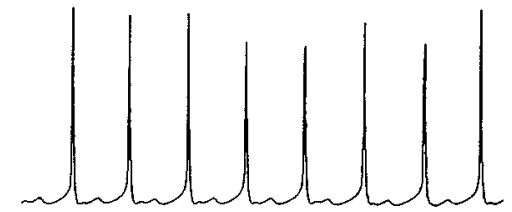

pyramidal cell 2

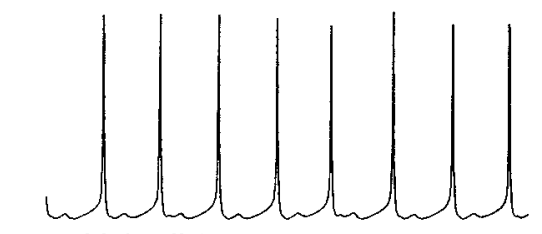

pyramidal cell 1

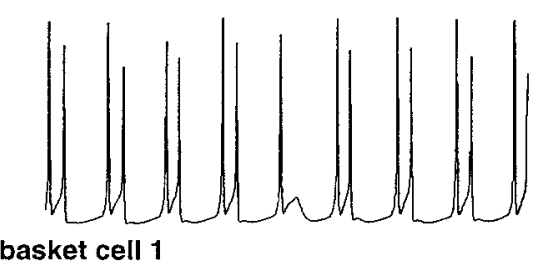

basket cell 1 pyramidal cell 2

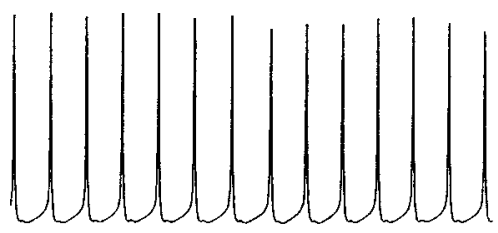

pyramidal cell 1

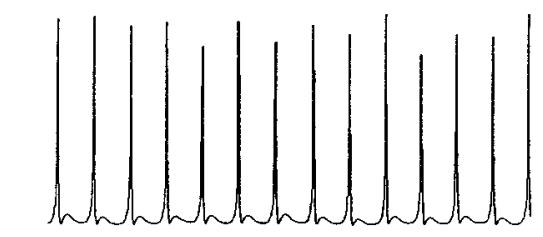

basket cell 1 simulated according to two paradigms. To represent two-site stimulation, driving conductances were applied to all of the neurons $(60+x \mathrm{nS}$ total for e-cells, $x$ ranging from 0 to $2.0 \mathrm{nS}$; and $10+x \mathrm{nS}$ for i-cells, $x$ ranging from 0 to $0.2 \mathrm{nS}$ ). To represent one-site stimulation, the same conductances were applied, but to cells in the left half of the array only. Pyramidal cells did not excite each other, and maximal $g_{\mathrm{K}(\mathrm{AHP})}$ was $0.25 \times$ its standard value. $A$, Intracellular potentials. With twosite stimulation (left), pyramidal cells on the right (e-cell 2) and left (e-cell 1) of the array oscillate synchronously. Interneurons fire doublets, or singlets followed by an EPSP, and the first spike in the doublet is approximately in phase with nearby pyramidal cells. With one-site stimulation (right), interneurons fire singlets only. $B$, Autocorrelations and cross-correlations of local averages of e-cell voltages (224 cells). With two-site stimulation, the two-site cross-correlation peak is at 1 msec. Note that oscillation frequency is higher with one-site stimulation (right, $62 \mathrm{~Hz}$ ) than with two-site stimulation (left, $41 \mathrm{~Hz}$ ). These results are in agreement with experimental data on in vitro $\gamma$ oscillations (Traub et al., 1996a,b; Whittington et al., 1997a).

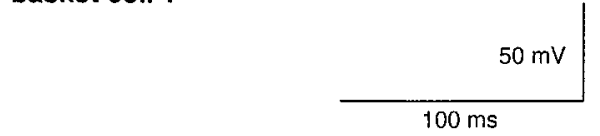

$B$
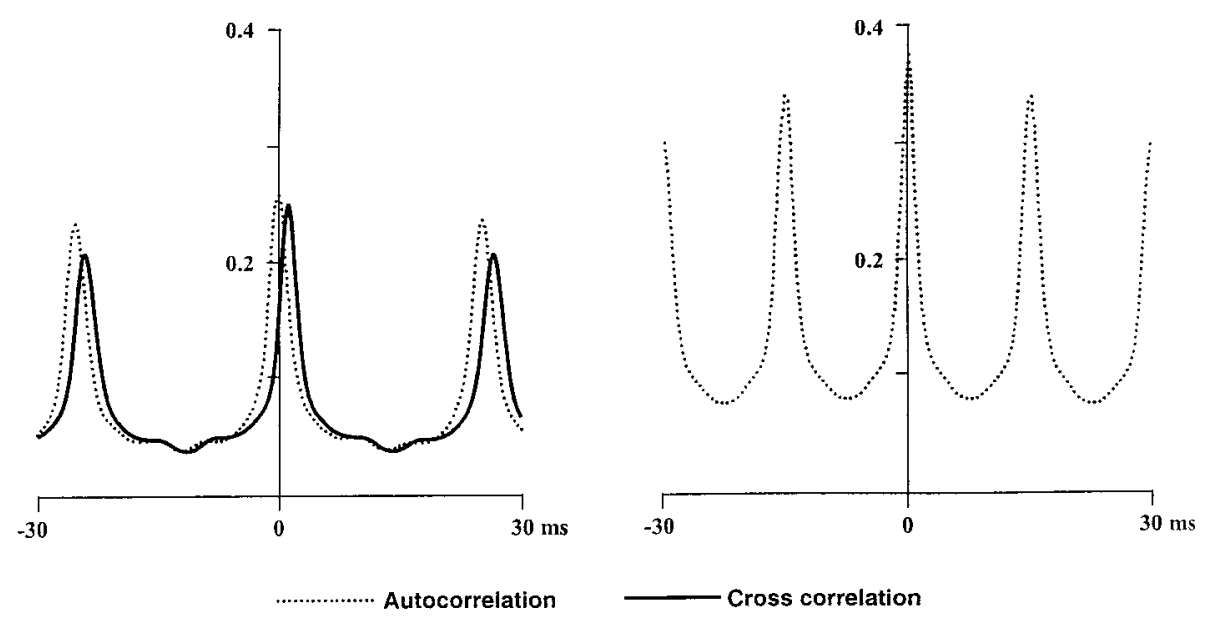

Whittington et al., 1997a), with the exception of (2), the specificity of interneuron doublet-firing for two-site (but not one-site) stimulation. The reason for this improved specificity of the present model is simple: there are long-range excitatory connections in the present model but not in the chain model. Instead, an interneuron in the chain model receives excitatory inputs from pyramidal cells in its own group and from pyramidal cells in immediately neighboring group(s). In the chain model, during a synchronized oscillation, the total excitatory input received by the interneuron will be the same, whether three groups or five groups are oscillating. However the unitary AMPA conductance is chosen, the interneuron either fires doublets (for a large conductance), or it does not (for a small conductance). On the other hand, when there are long-range excitatory connections, as well as local ones, then there is a range of unitary AMPA conductances such that (1) a local oscillation cannot induce doublets, but (2) a more global oscillation can.

We note that doublet firing by interneurons during CA1 twosite synchronized $\gamma$ oscillations is reminiscent of $\gamma$-frequency bursts in neocortical neurons, morphologically identified as aspiny (hence presumably inhibitory) cells (Steriade et al., 1998).

The simulations in Figure 2 were performed without recurrent excitation between pyramidal cells; such interactions do not appear to be necessary for $\gamma$ oscillations in CA1. Nevertheless, as Figure 4 will show, synchronized $\gamma$ oscillations can also exist in our model when there is recurrent pyramidal/pyramidal cell excitation, provided it is not too powerful.

We will present evidence that the long-range excitatory con- 
A

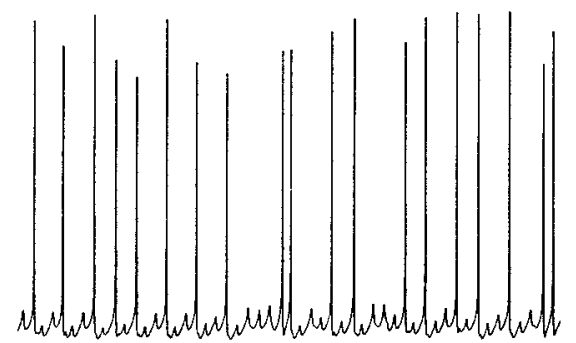

model

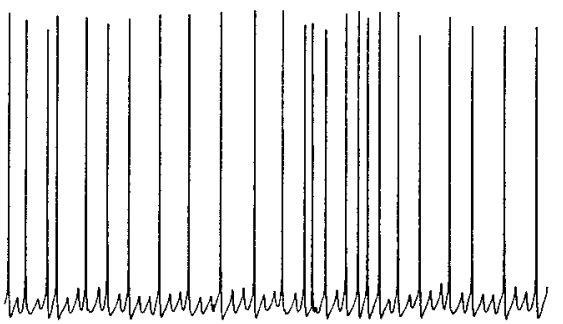

B

\section{experiment}

i

pyramidal cell control

pyramidal cell joro toxin

ii
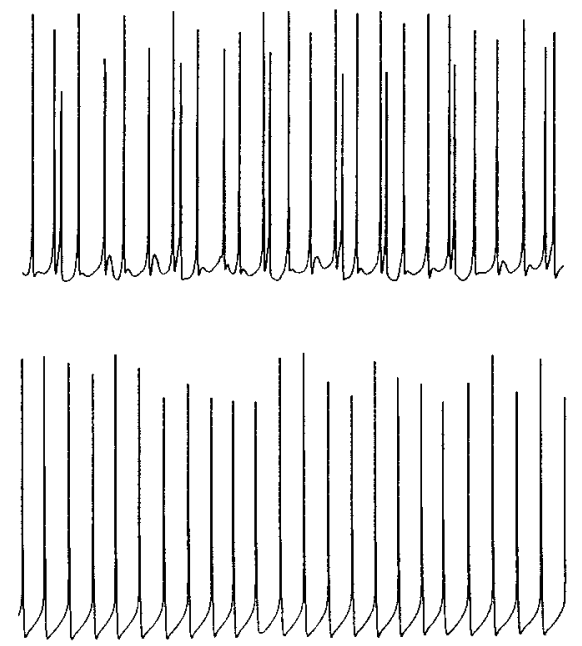

interneuron control
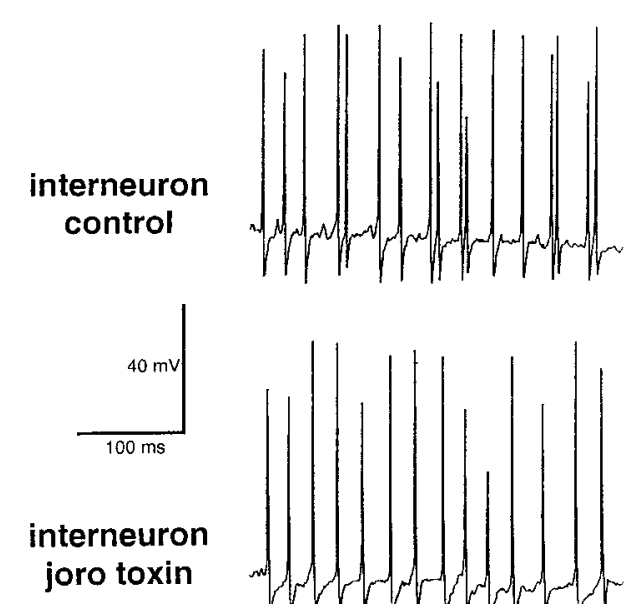
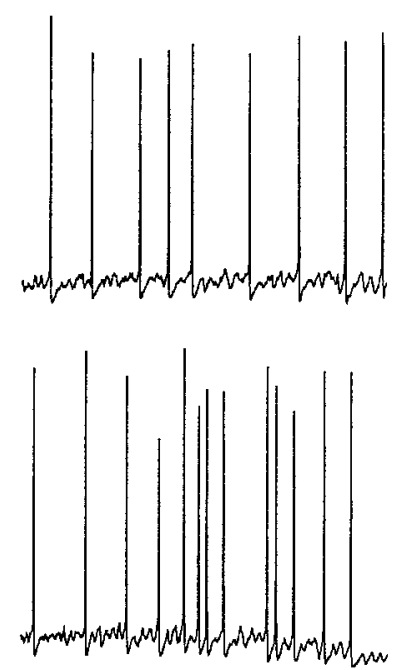

Figure 3. Effects of locally applied joro toxin on oscillations evoked by two-site stimulation: model and experiment. $A$, Simulation. The effect of locally applied joro toxin was simulated by blocking AMPA receptors on interneurons in the left half of the array. Near-uniform tonic excitatory conductances were applied to pyramidal cells and interneurons, as in Figure 2 (left). $g_{\mathrm{K}(\mathrm{AHP})}$ density was set at its standard value, and unitary pyramidal/pyramidal EPSCs were $0.75 \times t \times e^{-\mathrm{t} / 2} \mathrm{nS}$. Model interneurons in the left half of the array do not fire doublets [with their AMPA receptors blocked (cf. Whittington et al., 1997a, 1998)], whereas interneurons in the right half of the array do fire doublets. As a result, the two halves of the array tend to oscillate at different frequencies (Fig. 2), but the array halves are synaptically coupled by interneurons around their boundaries and by pyramidal cells globally. This in turn causes complex irregular firing patterns in the pyramidal cells. $B$, Experiment. Twosite oscillations were evoked by simultaneous tetanic stimulation in the CA1 region. Joro toxin $(0.1 \mu \mathrm{M})$, a blocker of interneuron AMPA receptors, was pressure-ejected onto the tissue near site 1 in stratum pyramidale. Cells were recorded near the site of toxin injection. The toxin produces irregularity in the firing patterns of pyramidal cells and abolishes interneuron doublets. Note the different time scales for pyramidal cells and interneurons. nections onto interneurons are important for understanding the two-site $\gamma$ desynchronization that follows twice-threshold stimulation of a single site.

\section{Effects of joro spider toxin}

Joro toxin relatively selectively blocks AMPA receptors lacking the GluR-B (GluR2) subunit. Such AMPA receptors are $\mathrm{Ca}^{2+}$ permeable and are more prevalent on interneurons than on pyramidal cells (Geiger et al., 1995; Iino et al., 1996), so that the toxin is relatively specific for interneurons. Experimental application of joro toxin during a tetanically evoked oscillation and simulation of its effects allow a further test of the model. Based on our understanding of the oscillation mechanisms, blockade of interneuron AMPA receptors in one region should lead to loss of interneuron doublets in that region. This loss would lead to two effects: the doublets would no longer be available to provide timing information to maintain synchrony (Ermentrout and Kopell, 1998), and the network oscillation frequency of the poisoned region would be faster than that of the unpoisoned region (if the latter is able to generate doublets), which would in turn lead to complex interference effects between the two regions.

Figure $3 A$ illustrates a simulation of the effects of joro toxin, obtained by blocking interneuron AMPA receptors in the left half of the array, whereas $g_{\mathrm{K}(\mathrm{AHP})}$ was at its "standard" value. (This value was used because the corresponding experimental recordings were obtained during the $\beta$ phase of the oscillation. Please note also the different time scales for pyramidal cells and interneurons.) As expected, interneurons in the left half fire only 
in singlets (Fig. 3Aii). In addition, interneurons in the right half of the array (data not shown), although able to fire doublets, do not fire nearly as many doublets as in comparable control simulations. This reduction in doublet incidence is related to the loss of two-site synchrony in this simulation (mean phase lag between the two sites, $5 \mathrm{msec}$ ). It will be recalled that excitatory input from both nearby and distant cells is required for interneuron doublet generation (Fig. 2) and that doublets are both a consequence of and a contributor to long-range synchrony. Pyramidal cells in this simulation demonstrate irregular firing patterns, which are not a consequence of any obvious irregularity in the firing patterns of the interneurons. The irregularity may result from recurrent EPSPs impinging on pyramidal cells from the two array regions, because they "try" to oscillate at different frequencies. Note that pyramidal cells fire on selected peaks of the intracellular $\gamma$ waves, which are generated by the interneuron network.

Figure $3 B$ illustrates data from experiments (four slices) in which joro toxin $(0.1 \mu \mathrm{M})$ was pressure-ejected near one stimulation site in CA1 stratum pyramidale, immediately after a two-site twice-threshold tetanic stimulation. Subsequent tetanically evoked oscillations (evoked at 4 min intervals) exhibited firing patterns as shown. Pyramidal cells during the $\beta$ phase of the oscillation fire on some of the peaks of intracellular $\gamma$ waves (Fig. $3 B i$, control), but after joro toxin application, pyramidal cells also can fire in rapid runs (Fig. 3Bi, bottom trace), as in the simulation. In control conditions, interneurons could fire spike doublets (Fig. 3 Bii), but such doublets were not observed after joro toxin (Fig. 3Bii, bottom trace), consistent with simulations and consistent with the expectation that the second spike in the interneuron doublet is evoked by AMPA receptor activation, the latter being reduced by joro toxin. The mean phase lag for four $\gamma$ oscillation epochs after joro toxin was $2.3 \mathrm{msec}$, versus $1.8 \mathrm{msec}$ for control oscillations (not statistically significant), i.e., there was less of an effect on phase than in the simulation.

\section{Mechanism of $\boldsymbol{\gamma} \rightarrow \boldsymbol{\beta}$ frequency shift}

Simultaneous increases in the amplitude of unitary EPSCs and of AHPs can account for the $\gamma \rightarrow \beta$ frequency shift

Whittington et al. (1997b) showed that during the transition from $\gamma$ to $\beta$ frequencies, two parameters in the neuronal system changed, with comparable time courses (over approximately 10 oscillation cycles or several hundred milliseconds): (1) pyramidal cell spike AHPs increased from a value of $<1 \mathrm{mV}$ to a value of $>4 \mathrm{mV}$, and (2) AMPA receptor-mediated EPSPs in pyramidal cells, in phase with the oscillation, increased from a value of $\leq 0.25 \mathrm{mV}$ to a value of $>2 \mathrm{mV}$. These EPSPs are not an epiphenomenon of increased firing synchrony of the pyramidal cells, because the magnitude of population spikes does not increase, and may even decrease, over the time interval in question; thus, the increase in EPSP size is presumed to reflect a true increase in the magnitude of unitary EPSCs at recurrent CA1 pyramidal cell/pyramidal cell connections.

During the period when spike AHPs and EPSPs are increasing, pyramidal cells remain depolarized (Whittington et al., 1997b). In view of the apparent increase in $\mathrm{K}^{+}$current(s) over this period, it is unlikely, therefore, that the metabotropic glutamate receptormediated conductance, induced by the tetanic stimulation (Whittington et al., 1997a), diminishes much during the $\beta$ oscillation.

Figure 4 illustrates a simulation in which tonic excitatory conductances to pyramidal cells and to interneurons were kept constant. For the first $800 \mathrm{msec}$ of the simulation, maximum
$g_{\mathrm{K}(\mathrm{AHP})}$ was held constant at $0.25 \times$ its usual value, and unitary pyramidal/pyramidal EPSCs were $0.75 \times t \times e^{-\mathrm{t} / 2} \mathrm{nS}$. During this time, the array generated a $\gamma$ frequency oscillation, synchronized across the array to within $1 \mathrm{msec}$; pyramidal cells fired singlets and interneurons fired either doublets or singlets followed by EPSPs. Subsequently, during the interval shown by the ramp (800-1200 msec from simulation onset), linearly in time, maximum $g_{\mathrm{K}(\mathrm{AHP})}$ was increased fourfold (to its standard value) and unitary EPSC amplitude was increased 4.6-fold. Both local and long-range EPSCs were increased in tandem. In the course of the 800-1200 msec interval, and after it, oscillation frequency slows from 52 to $\sim 14 \mathrm{~Hz}$; the large EPSPs in a hyperpolarized pyramidal cell during the $\beta$ phase indicate that the $\beta$ oscillation is synchronized, as do local average potentials (data not shown). In the $\beta$ phase, pyramidal cells fire occasional doublets [as occurs experimentally (Whittington et al., 1997b)], and interneurons fire in bursts, as well as singlets and doublets. Autocorrelations and cross-correlations of average pyramidal cell signals are shown in Figure $4 B$. Note that during the $\beta$ phase (Fig. $4 B i i$ ), there is a smaller $\gamma$ peak at $30 \mathrm{~Hz}$, slower than the frequency during the initial $\gamma$ oscillation (Fig. $4 \mathrm{Bi}$ ); this slowing is a consequence, in part, of interneuron bursts.

The $\beta$-phase EPSPs in Figure 4 reach $\sim 10 \mathrm{mV}$, whereas experimental $\beta$-phase EPSPs are $<5 \mathrm{mV}$. It is possible that model neurons, in which EPSPs are pictured, are more hyperpolarized than corresponding real neurons, an effect that would increase EPSP size.

We repeated the simulation of Figure 4, but with tonic driving conductances delivered to pyramidal cells and interneurons in the left half of the array only, with maximum $g_{\mathrm{K}(\mathrm{AHP})}$ and unitary EPSCs evolving as in Figure 4. This simulation (data not shown) verified that the model could replicate the $\gamma \rightarrow \beta$ shift induced by strong stimulation at a single site (Whittington et al., 1997b).

In summary, in simulations, an increase in $g_{\mathrm{K}(\mathrm{AHP})}$ with a simultaneous increase in unitary pyramidal/pyramidal EPSCs (that is, sufficiently large) produces a "switch" from synchronized $\gamma$ to a synchronized $\beta$ oscillation. The latter contains "underlying" $\gamma$ that is generated by the interneuron network, pyramidal cell doublets (on occasion), and interneuron bursts.

Clear $\gamma \rightarrow \beta$ frequency shifts have been recorded intracellularly in $>50$ pyramidal cells and in two interneurons in the course of this study. Examples are shown in Figure $5 A$. This particular pyramidal cell did not exhibit spike doublets during $\beta$; an example of pyramidal cell spike doublets is shown in Whittington et al. (1997b, their Fig. 1Cc). Subthreshold membrane fluctuations are clearly seen during the $\beta$ phase of the pyramidal cell in Figure $5 A$ (compare Fig. 4A). The interneuron (not recorded simultaneously with the pyramidal cell) fires in a complex mixture of single spikes, doublets, triplets, and quadruplets during the $\beta$ phase, as occurs also in the simulation (Fig. 4).

EPSPs synchronized with population spikes were shown previously to occur in hyperpolarized pyramidal neurons during the $\beta$ oscillation (Whittington et al., 1997b). Figure $5 B$ provides additional evidence that these EPSPs represent a network phenomenon. In CA1, pyramidal cell $\rightarrow$ pyramidal cell connections are believed to form predominantly in stratum oriens (Deuchars and Thomson, 1996). Figure $5 B$ shows a $\gamma \rightarrow \beta$ transition in which extracellular potentials were recorded simultaneously in stratum pyramidale and stratum oriens, the recordings beginning immediately after the stimulus artifacts. Note that most of the extracellular potentials in stratum oriens increase in amplitude as the $\beta$ oscillation develops, whereas there is little activity in stratum 
$\boldsymbol{A}$

pyramidal cell
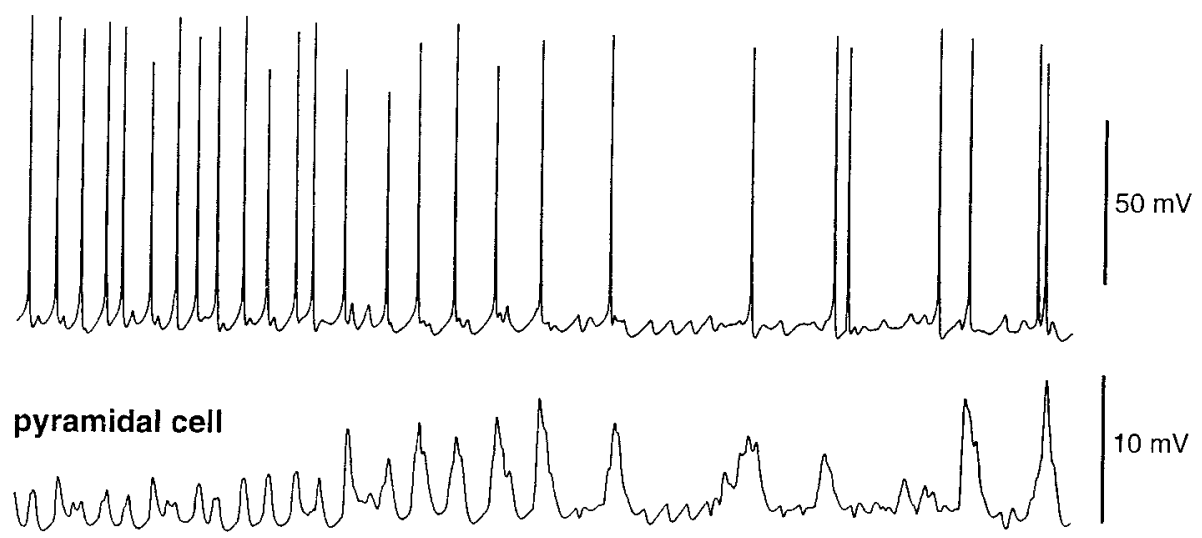

basket cell

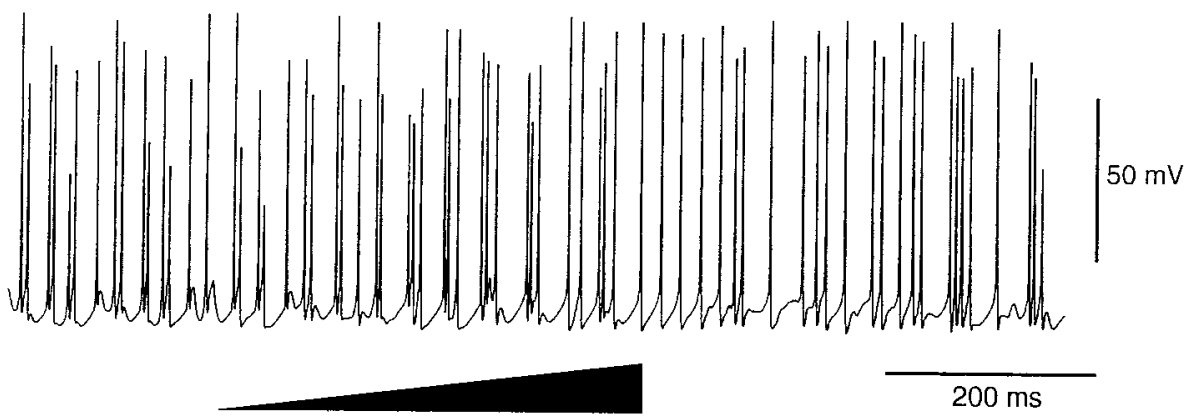

Figure 4. Firing patterns of pyramidal cells and interneurons during $\gamma$ and $\beta$ oscillation: simulation. The $\gamma / \beta$ switch was simulated by applying tonic excitatory conductances to pyramidal cells and interneurons, with maximal $g_{\mathrm{K}(\mathrm{AHP})}$ at $0.25 \times$ its standard value and unitary pyramidal $/$ pyramidal EPSCs $0.75 \times t \times e^{-\mathrm{t} / 2}$. Starting at $800 \mathrm{msec}$ after onset of the run, and until $1200 \mathrm{msec}$ (shown by the ramp), maximal $g_{\mathrm{K}(\mathrm{AHP})}$ and unitary EPSCs increased, linearly in time to new values that then remained constant. The new values were maximal $g_{\mathrm{K}(\mathrm{AHP})}=$ standard value, unitary pyramidal/pyramidal EPSC $3.45 \times$ $t \times e^{-\mathrm{t} / 2} \cdot A$, Two pyramidal cells (at $x=5$ and $x=91$, the latter hyperpolarized with $3 \mathrm{nA}$ current to reveal EPSPs), and a basket cell. During the $\gamma$ oscillation, pyramidal cells fire singlets, and interneurons fire doublets or singlets followed by EPSPs. As $g_{\mathrm{K}(\mathrm{AHP})}$ and unitary EPSCs increase, the pyramidal rhythm slows to $\beta$ frequency, pyramidal cells sometimes fire doublets, and interneurons fire singlets, doublets, and bursts. During the $\beta$ phase, pyramidal cells exhibit subthreshold synaptic potentials at $\gamma$ frequency [see also Whittington et al. (1997b)]. B, Autocorrelations and cross-correlations of e-cell average signals, during the $\gamma$ phase $(i, 52 \mathrm{~Hz}$, phase lag between sites $1.7 \mathrm{msec}$ ), and during the $\beta$ phase (ii, $14.3 \mathrm{~Hz}$ ). During the $\beta$ phase, there is a small peak in the autocorrelation at $\gamma$ frequency $(30 \mathrm{~Hz})$.

radiatum, during either the $\gamma$ or $\beta$ phases. This experiment gave similar results in three slices. These data suggest that the increasing amplitude stratum oriens potentials are field EPSPs and the extracellular correlates of the EPSPs recorded intracellularly during the $\beta$ phase (Whittington et al., 1997b).

\section{Effects of increasing $g_{\mathrm{K}(\mathrm{AHP})}$ or recurrent EPSPs, but not both together}

In simulations, it is possible to manipulate, independently, maximal $g_{\mathrm{K}(\mathrm{AHP})}$ and unitary EPSC amplitude. In Figure 6, the simulation of Figure 4 was repeated, but over the $800-1200 \mathrm{msec}$ interval after onset of the run (shown by the ramp), unitary EPSCs (pyramidal/pyramidal) were increased only twofold, in- stead of 4.6-fold, whereas maximal $g_{\mathrm{K}(\mathrm{AHP})}$ was increased fourfold, as before. In the present case, individual pyramidal cell firing rates decrease to the $\beta$ range (Fig. 6, top trace), at least transiently, but firing in the $\beta$ phase is not synchronized. This fact is indicated by the population EPSPs in a hyperpolarized pyramidal cell, which are about the same amplitude in the $\beta$ phase as in the $\gamma$ phase, despite the twofold increase in unitary EPSC amplitude (Fig. 6, middle trace). In addition, pyramidal cells never fire spike doublets, because the second spike in a pyramidal doublet (in CA1) is recruited synaptically by the pyramidal cell population firing during the first spike, analogous to what happens with interneuron doublets. Without pyramidal cell doublets in the $\beta$ phase, interneurons continue to fire singlets and doublets and 


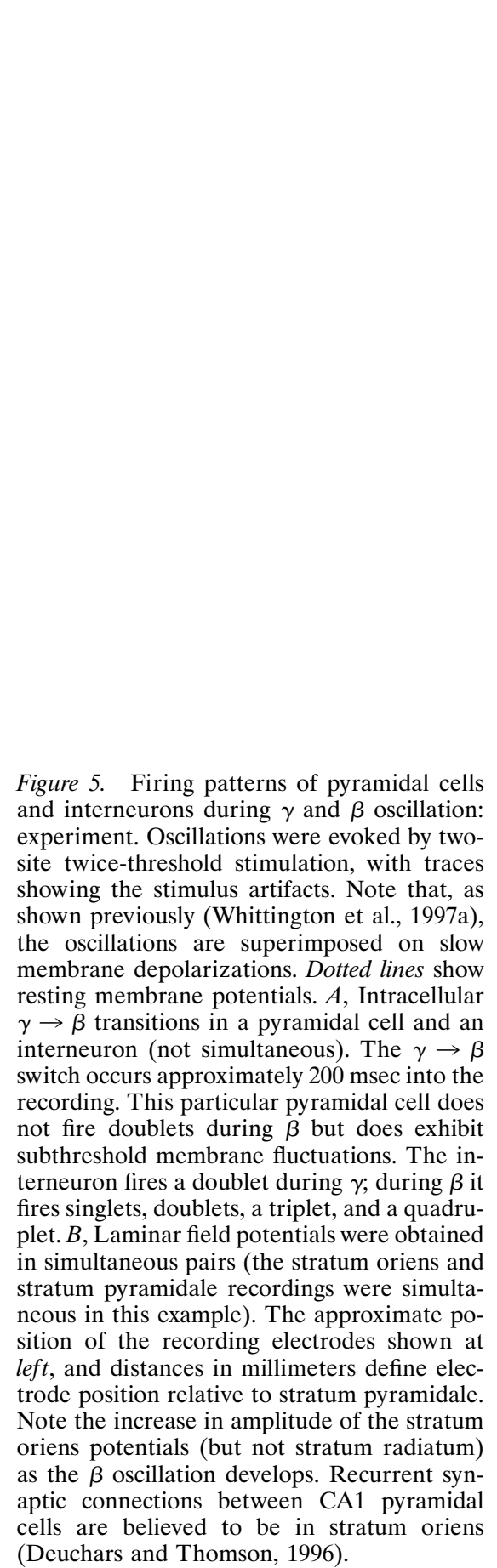

A

\section{intracellular}

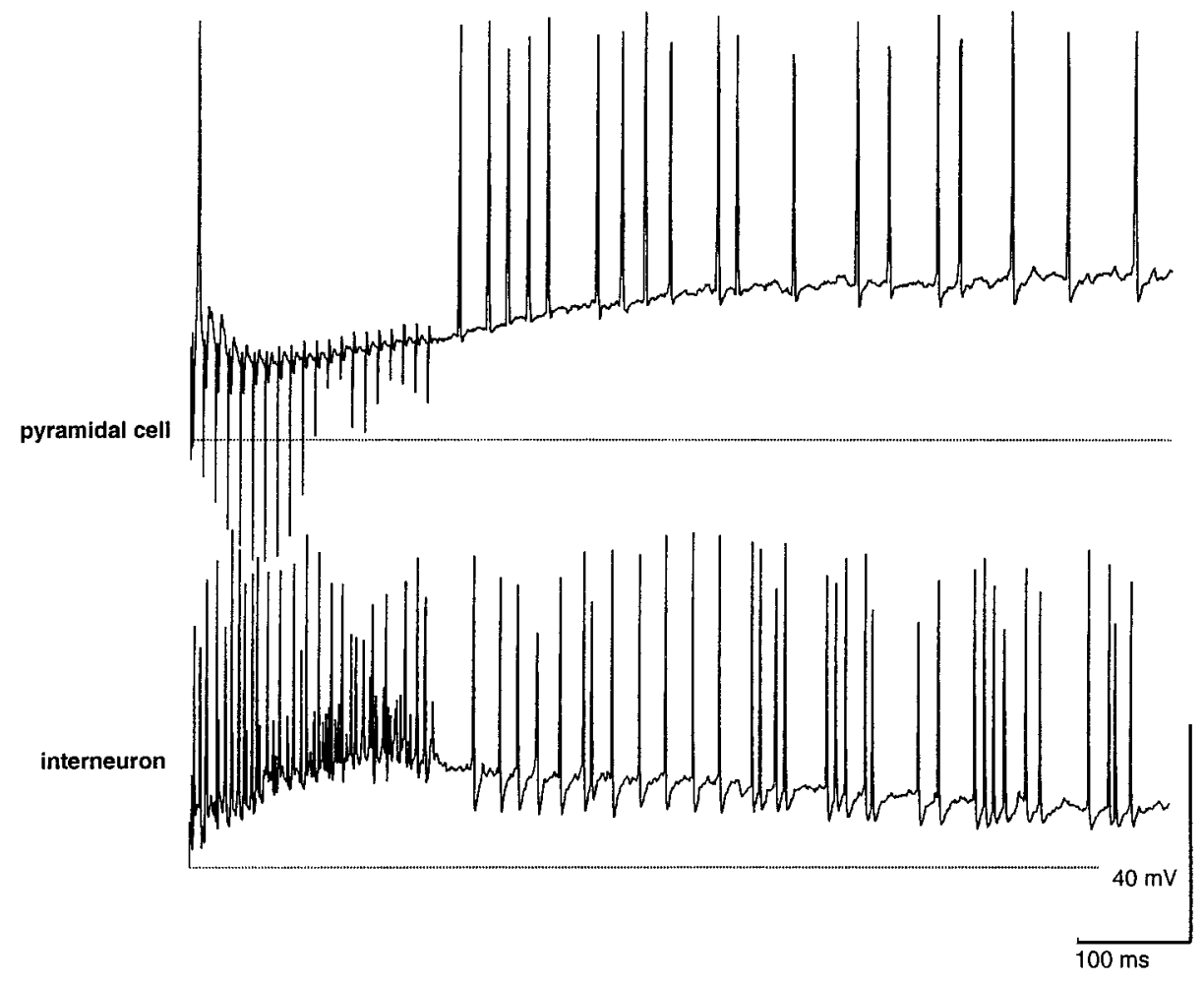

B

\section{extracellular}

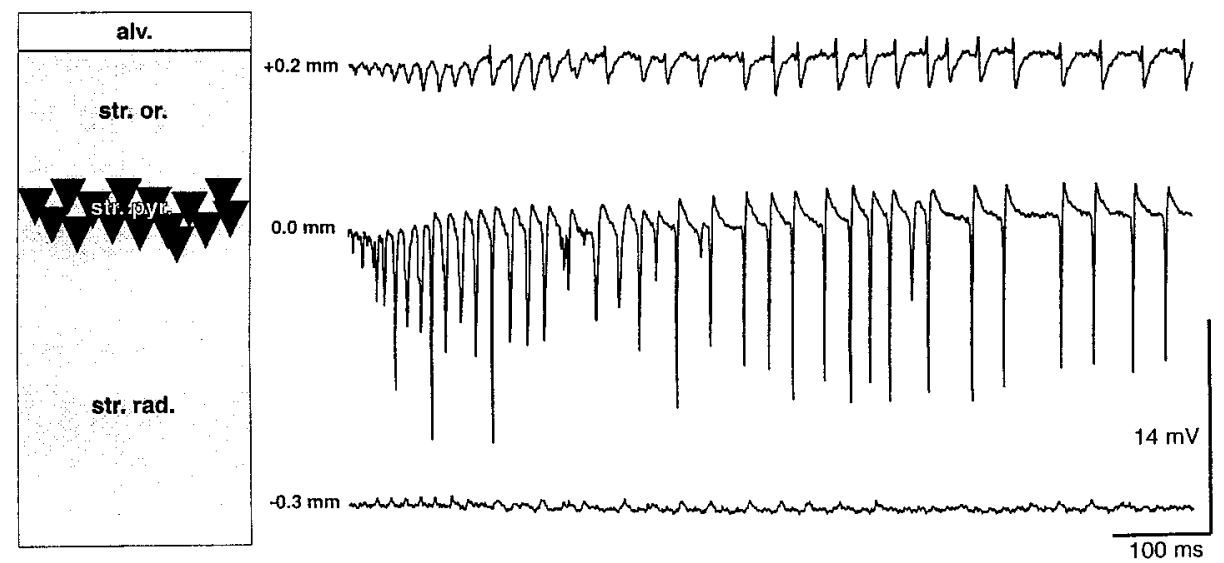

do not fire bursts. These cellular behaviors do not correspond to experimental $\gamma / \beta$ shifts. The simulation of Figure 6 , however, may capture what happens as a $\gamma$ oscillation breaks apart at the population level, when an organized $\beta$ phase fails to occur.

The data in Figure 6 suggest that sufficiently large AMPA receptor-mediated, pyramidal/pyramidal EPSC increases are necessary for a synchronized $\beta$ oscillation to develop. Whittington et al. (1997b) used pressure ejection of NBQX to provide evidence that the $\beta$ phase EPSCs are indeed dependent on AMPA receptors. One expects, therefore, that pressure ejection of NBQX would also prevent a switch to a synchronized $\beta$ oscillation from occurring, as measured with field potential recordings. The data of Figure 7 indicate that this is indeed the case. In experiments in six slices, $\gamma / \beta$ oscillations were evoked by two-site twice-threshold stimuli under control conditions (Fig. 7A). Puffing on NBQX (20 $\mu \mathrm{M}, \square)$ midway between the stimulation sites prevented an abrupt $\beta$ shift (Fig. 7B), although oscillation frequency does slow gradually, as normally occurs with $\gamma$ oscillations (Whittington et al., 1997b, their Fig. 1Ba); $\gamma$ oscillations were also prolonged in these instances, for reasons that were not clear. Note as well that NBQX additionally increases $\gamma$ oscillation frequency and disrupts two-site $\gamma$ synchrony (cross-correlations in Fig. 7Aii, Bii), an effect predicted by our model and previously shown experimentally (Whittington et al., 1997a). 
A

pyramidal cell
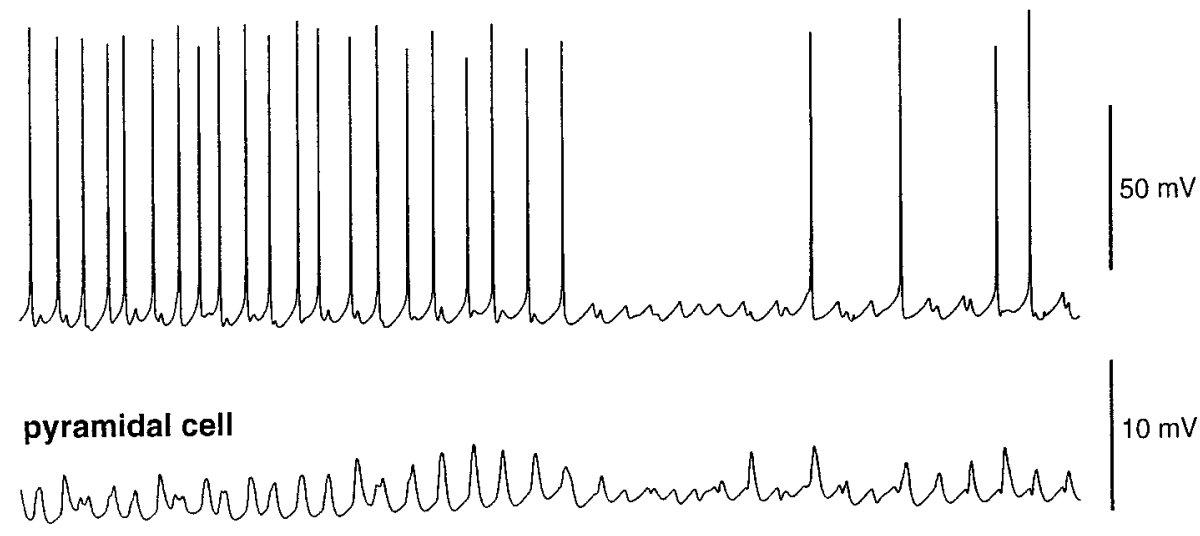

Figure 6. When $g_{\mathrm{K}(\mathrm{AHP})}$ increases during the $\gamma$ oscillation but EPSPs fail to develop, individual pyramidal cells fire at $\beta$ frequencies, but asynchronously (simulation). The simulation was identical to that of Figure 4, with maximal $g_{\mathrm{K}(\mathrm{AHP})}$ increasing fourfold over the time interval 800-1200 msec (ramp), but in the present case, unitary EPSCs only double over this time interval rather than increasing 4.6-fold. We again illustrate pyramidal cells (at $x=5$, and a hyperpolarized one at $x=91$ ), and a basket cell. In the present case, individual pyramidal cell firing slows once $g_{\mathrm{K}(\mathrm{AHP})}$ has increased, and cells "skip beats" of the underlying $33 \mathrm{~Hz}$ population rhythm. Because pyramidal cells do not fire doublets in this case, interneurons do not burst but instead fire singlets and doublets. These singlets and doublets occur at $\gamma$ frequency (albeit slower than the original $\gamma$ frequency in the simulation, $52 \mathrm{~Hz}$ ), and induce rhythmic synaptic potentials in pyramidal cells.

In comparing the simulation of Figure 6 with the experiments in Figure 7, it is important to note that the simulation shows the potentials of individual cells, whereas the experiment is illustrated with field potentials. Although individual cells in simulations slow their firing rates to the $\beta$ range, this slower firing-not being synchronized, when recurrent EPSPs are not enhanced enough-would not be expected to show up in field potential recordings. Only the synchronized $\gamma$ oscillation would be expected to be manifest in field potential recordings under such conditions.

In the case illustrated in Figure $8 A$, the simulation of Figure 4 was repeated, but this time maximal $g_{\mathrm{K}(\mathrm{AHP})}$ was kept constant, whereas unitary pyramidal/pyramidal EPSCs were increased 4.2fold (a bit less than in Fig. 4). The $\beta$ phase now resembles an epileptic afterdischarge, with both pyramidal cells and interneurons firing in bursts at $\sim 20 \mathrm{~Hz}$ in a pattern not usually observed experimentally. $\beta$-phase EPSPs in hyperpolarized pyramidal cells, in the present case, have a duration of almost $50 \mathrm{msec}$, but experimental $\beta$-phase EPSPs can be almost this broad (Whittington et al., 1997b). Similar afterdischarge-like firing patterns were observed in two slices, although at lower frequency $(\sim 4 \mathrm{~Hz})$ (Fig. $8 B$ ); however, we do not have data to show that the repeating bursts resulted from a relative attenuation of AHP conductances.

\section{Persistent effects of twice-threshold tetanizations that induce $\boldsymbol{\beta}$ oscillations}

Persistent $\beta$ synchrony

In Whittington et al. (1997b), it was shown that a single administration of a twice-threshold stimulus (one that elicited a $\beta$ oscillation) would alter circuit properties, so that later threshold stimuli would also each elicit a $\beta$ oscillation, stimuli of intensity too weak to elicit a $\beta$ oscillation under control conditions. An example of this phenomenon with two-site stimulation, in which tetanic stimuli were delivered to the two sites every $4 \mathrm{~min}$, is shown clearly in Figure 9. Under control conditions (Fig. 9A), a threshold stimulus evoked $\gamma$ activity only. When one delivery of twice-threshold stimulation was administered simultaneously to both sites (Fig. 9B), a $\gamma \rightarrow \beta$ transition occurred. After this, later threshold stimuli could now evoke $\gamma \rightarrow \beta$ transitions. This effect of twice-threshold stimulation was observed in five slices.

We should note as well that a single administration of a two-site twice-threshold stimulus also produces long-lasting changes in recurrent CA1 pyramidal cell $\rightarrow$ pyramidal cell excitatory synaptic connections. This was shown by Whittington et al. (1997b), who observed that pairs of pyramidal cells existed with these properties: (1) under control conditions, spikes in cell 1 failed to elicit EPSPs in cell 2; (2) during an oscillation evoked by two-site twice-threshold stimulation, spikes in cell 1 did elicit EPSPs in cell 2; and (3) during later oscillations, evoked by threshold stimuli, spikes in cell 1 still elicited EPSPs in cell 2. The data presented so far suggest that persistent effects on EPSPs and on $\beta$ oscillations are causally related (see Discussion).

\section{A mechanism for desynchronizing $\gamma$ oscillations at the two sites} How can one account for a type of synchrony modulation that is converse to the one described above (the enhancement of $\beta$ synchrony after two-site twice-threshold stimulation)? That is, we must explain why, after a single episode of one-site twicethreshold tetanus, $\gamma$ oscillations subsequently evoked by two-site 


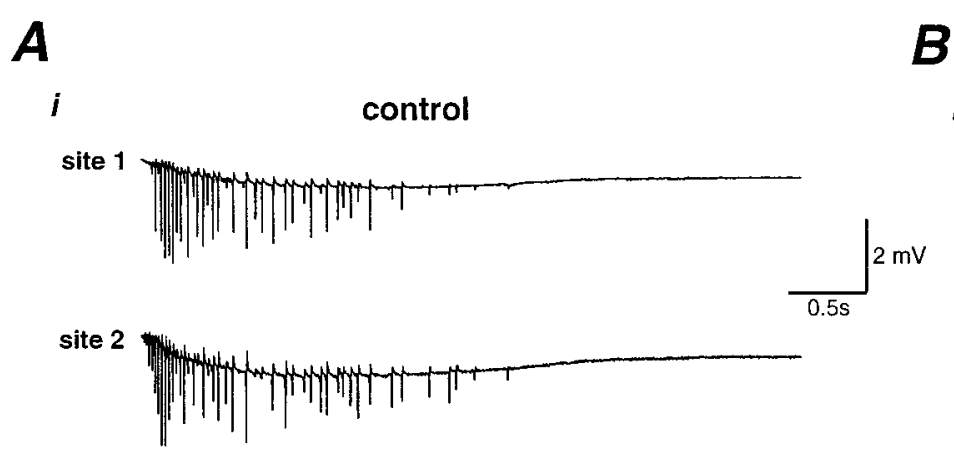

ii

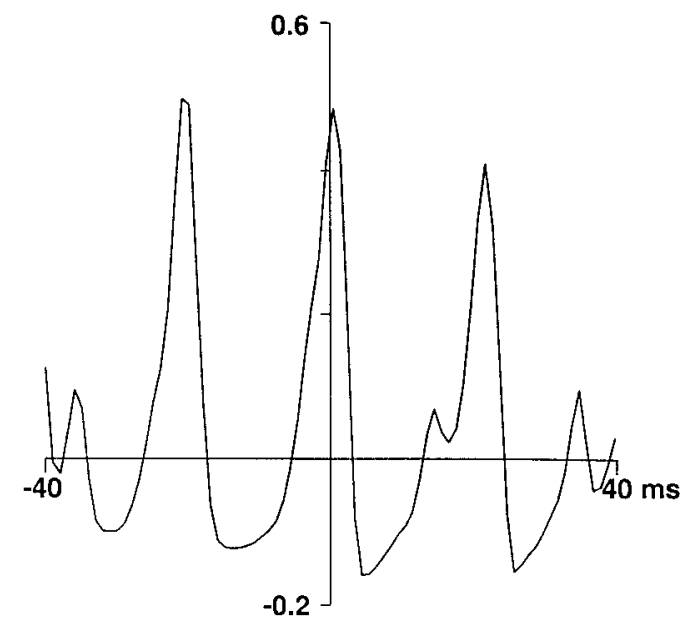

B

i NBQX

site 1

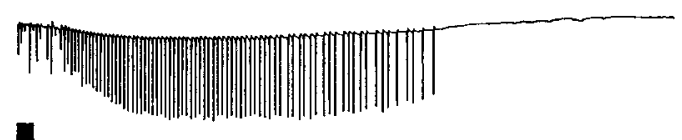

site 2

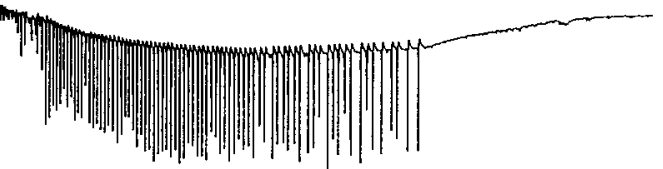

ii

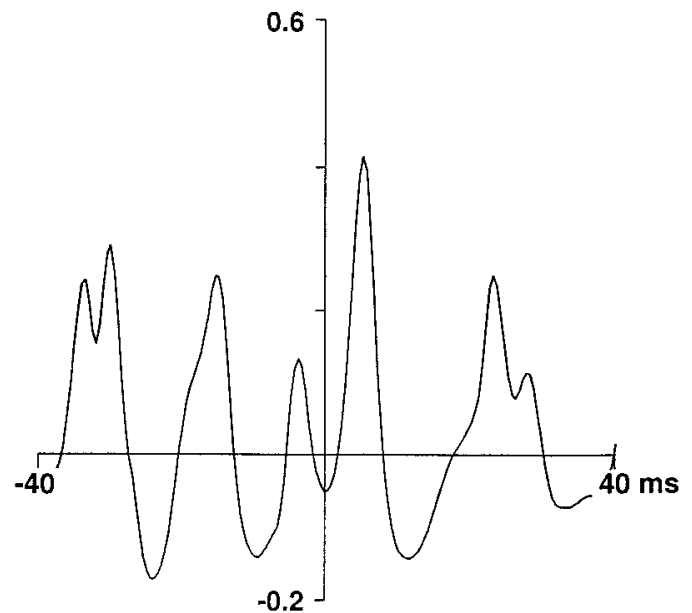

Figure 7. NBQX prevents the $\gamma \rightarrow \beta$ frequency shift. Concurrent extracellular recordings (beginning immediately after the stimulus artifact), from the same slice, with two-site twice-threshold tetanic stimulation in each case. $A$, Control case. A $\gamma \rightarrow \beta$ transition occurs. Cross-correlation (below) of the first $200 \mathrm{msec}$ of the $\gamma$ oscillation shows tight synchrony (phase lag near 0 ) and frequency $47 \mathrm{~Hz}$. B, Puffing on NBQX $(20 \mu \mathrm{M}, \mathbf{\square})$ at a site midway between sites 1 and 2 prevents $\beta$ oscillation but not $\gamma$ oscillation. For reasons that are not clear, the $\gamma$ oscillation is prolonged. [Note that NBQX in the bath does eventually block tetanically induced $\gamma$ oscillations (Whittington et al., 1997a).] Consistent with previous results (Whittington et al., 1997a), NBQX increases oscillation frequency (to $55 \mathrm{~Hz}$ ) and increases the two-site phase lag (to $5.6 \mathrm{msec}$ ).

threshold tetani do not synchronize between the two sites (Whittington et al., 1997b). One possibility considered by Whittington et al. (1997b) was that the one-site twice-threshold stimulus induced strong enough recurrent, pyramidal/pyramidal EPSPs that pyramidal cell spike doublets would occur in the $\gamma$ phase of subsequent oscillations. Pyramidal cell doublets in the intensely stimulated site, but not in the other site, would prevent synchrony, because the two sites would "try" to oscillate at different frequencies, the site with doublets oscillating more slowly. This explanation, however, appears unlikely for two reasons: (1) pyramidal cell doublets are rarely observed during CA1 $\gamma$ oscillations, even after a strong tetanus [although such doublets do occur in subiculum, wherein intrinsic cell properties contribute (Stanford et al., 1998)], and (2) EPSPs usually do not occur in pyramidal cells until toward the end of the $\gamma$ phase of the oscillation.

An alternative possible explanation is that one-site twicethreshold tetanic stimulation induces persistent depression of long-range pyramidal $\rightarrow$ interneuron synapses (depression of long-range pyramidal $\rightarrow$ pyramidal synapses in CA1 would not be expected to influence $\gamma$ synchrony, because EPSPs are not well developed during $\gamma$ in any case). The idea is that depression of long-range pyramidal $\rightarrow$ interneuron synapses, if sufficiently developed, would suppress interneuron doublets (Fig. 2) (Traub et al., 1996a,b; Whittington et al., 1997a) and so prevent longrange $\gamma$ synchrony.

The simulation in Figure 10 illustrates this possibility. Parameters were chosen such that a globally synchronized $\gamma$ oscillation would occur, as in the $\gamma$ phase of Figure 4 (maximal $g_{\mathrm{K} \text { (AHP) }}$ $0.25 \times$ its standard value, unitary pyramidal/pyramidal EPSC $\left.0.75 \times t \times e^{-\mathrm{t} / 2} \mathrm{nS}\right)$, but the simulation was performed with a change in the synaptic excitation of interneurons: pyramidal $\rightarrow$ interneuron connections, in which presynaptic and postsynaptic cells were on opposite sides of the array, had their maximum conductance reduced by $90 \%$. This prevented interneuron doublets, and the mean phase lag between the two sides increased from $1.7 \mathrm{msec}$ (control conditions) to $5.6 \mathrm{msec}$ (when long-range pyramidal cell $\rightarrow$ interneuron connections were depressed).

Experimentally, it was possible to record from two interneurons long enough to test portions of this hypothesis. An example is shown in Figure 11. In each case, the field potential was recorded near site 1 , while an interneuron was recorded intracellularly near site 2 . A control two-site threshold tetanic stimulation evoked a $\gamma$ oscillation of declining frequency, with interneuron singlets and doublets (Fig. 11 $A$ ). Cross-correlation of the initial portion of this oscillation (field vs interneuron) produced an inverted peak at $-2.0 \mathrm{msec}$ (the "peak" is negative because the 
A

\section{pyramidal cell}
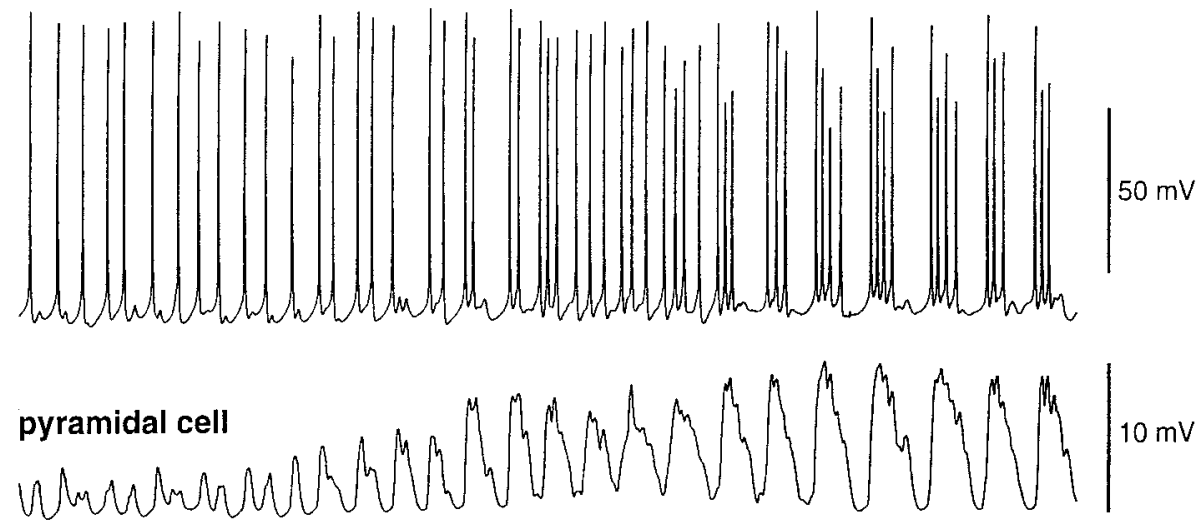

basket cell

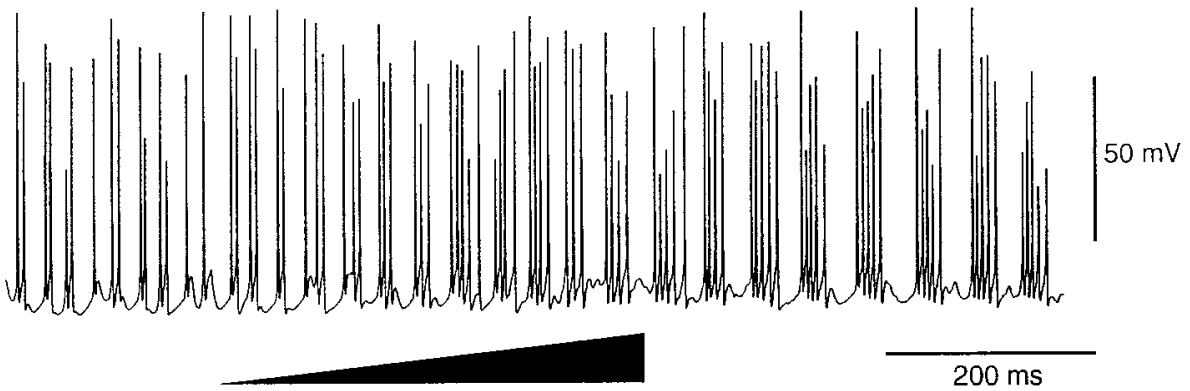

B experiment

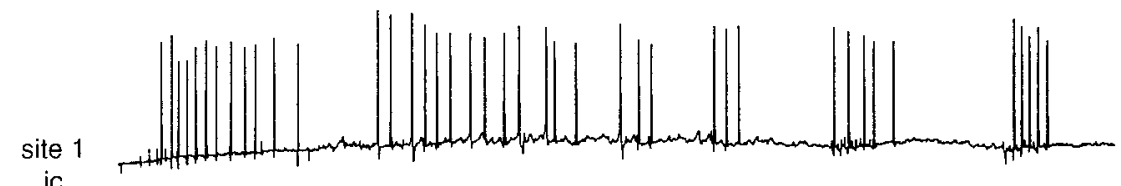

ic

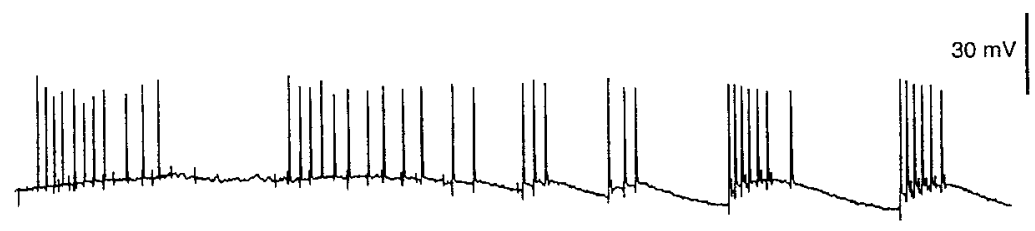

ic
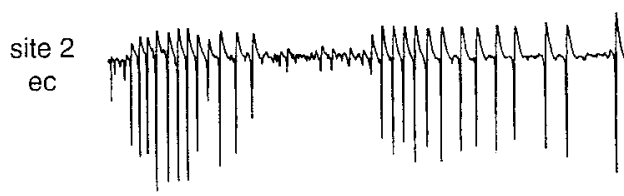

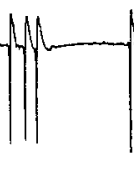

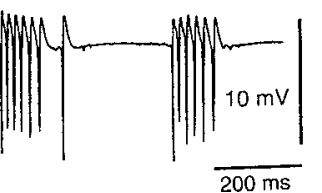

Figure 8. When EPSPs develop during the $\gamma$ oscillation but $g_{\mathrm{K}(\mathrm{AHP})}$ fails to increase, synchronized bursts occur. Similar behavior can be seen experimentally. $A$, Simulation. The simulation was as in Figure 4, but during the 800-1200 msec time interval (relative to the onset of the run, ramp), maximum $g_{\mathrm{K}(\mathrm{AHP})}$ remains constant while unitary pyramidal/pyramidal EPSCs increase in amplitude 4.2-fold. As usual, we illustrate two pyramidal cells [at $x=5$, and a hyperpolarized one ( $-3.0 \mathrm{nA}$ current $)$ at $x=91]$ and a basket cell $(x=5)$. In the present case, the $\gamma$ oscillation is succeeded by bursts, at $\sim 20 \mathrm{~Hz}$, in both pyramidal cells and interneurons. $B$, Experiment. Simultaneous dual intracellular recordings (pyramidal cells) and field potential showing transition from $\gamma$ oscillation to epileptic afterdischarge at $\sim 4 \mathrm{~Hz}$. Recordings begin immediately after the stimulus artifact. The first $200 \mathrm{msec}$ of $\gamma$ activity was synchronized between the two sites to within $1 \mathrm{msec}$. two signals have opposite signs). Four oscillatory episodes were then evoked by stimulating site 1 with twice-threshold intensity, recording meanwhile from the interneuron at site 2 while the latter was hyperpolarized to $-80 \mathrm{mV}$ (near $\mathrm{GABA}_{\mathrm{A}}$ receptor reversal potential) by passage of current through the electrode. The oscillatory episodes were $4 \mathrm{~min}$ apart, and three of them are shown in Figure $11 B$. What is clear is that each successive site 1 oscillation is associated with less excitatory synaptic activity in the interneuron. (The depolarizing potentials in the interneuron are unlikely to be reversed IPSPs, because the tetanus was delivered to the opposite site, $>1.5 \mathrm{~mm}$ away, and it is at this distant site where interneurons would be firing.) After these four oscillatory episodes, a repeat two-site threshold tetanic stimulus failed to evoke interneuron doublets (Fig. 11C). Loss of interneuron doublets was observed as late as 8 min after the last one-site twicethreshold stimulus to the opposite site, after which the cell was lost. Furthermore, the cross-correlation signal (Fig. 11C, right), although it has an inverted peak at $2 \mathrm{msec}$, is disorganized. This occurs because of varying phase relations between successive interneuron spikes/population spikes.

A quantitative summary of the data for EPSPs in the two interneurons, for the first $200 \mathrm{msec}$ of oscillations evoked by twice-threshold stimulation of the opposite site, is as follows. For the first interneuron, there were 12 EPSPs of amplitude $2.4 \pm 0.2$ 

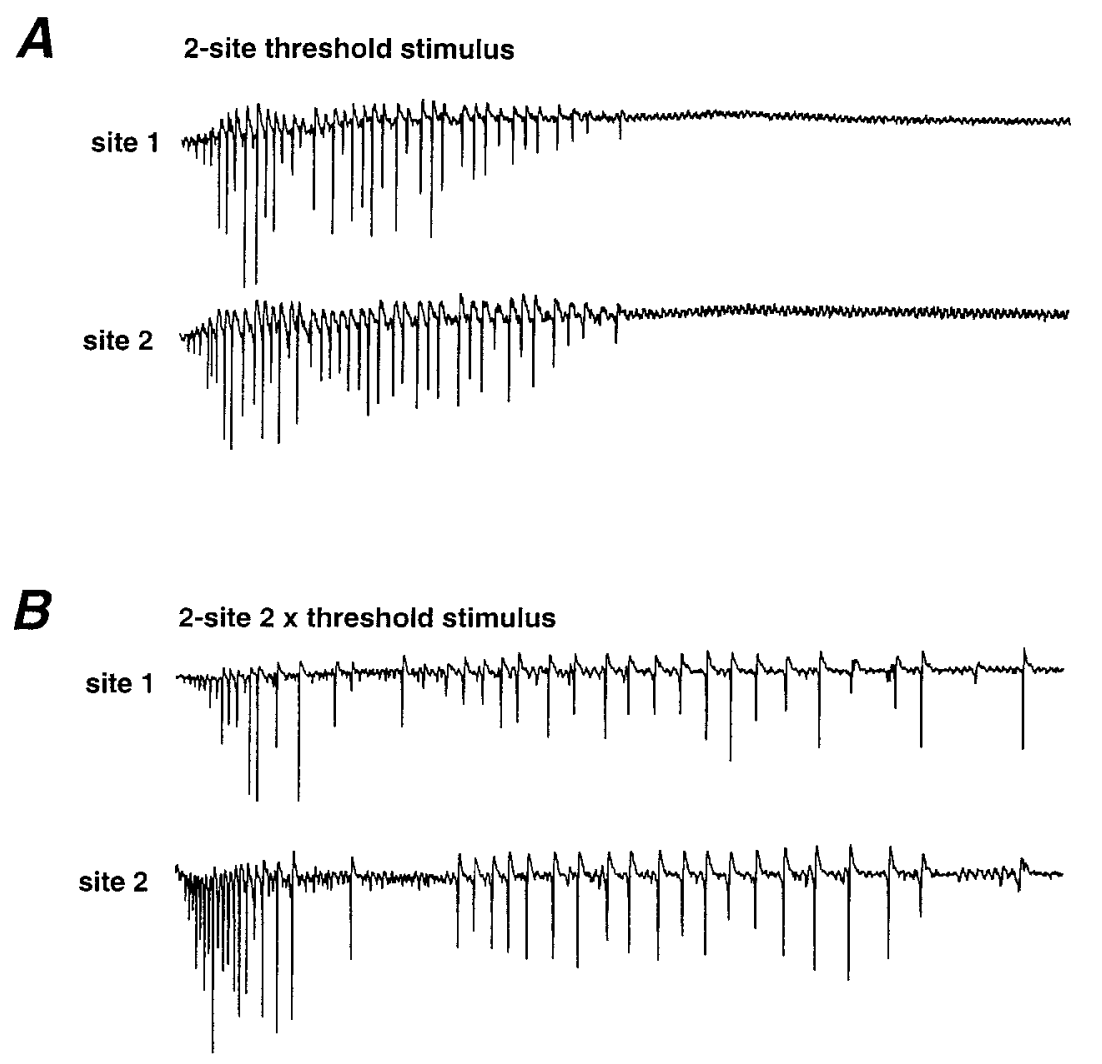

Figure 9. Beta oscillation induced by two-site twicethreshold stimulation recurs when two-site threshold stimulation is later applied. Two-site field potentials (recordings begin immediately after stimulus artifact) are concurrent. Stimuli are given every $4 \mathrm{~min}$. $A$, Twosite threshold stimulus evokes $\gamma$ oscillations only. $B$, Two-site twice-threshold stimulus evokes $\gamma \rightarrow \beta$ transition. $C$, Later two-site threshold stimulus now evokes $\gamma \rightarrow \beta$ transition. [Repeating threshold stimuli by themselves do not elicit $\gamma \rightarrow \beta$ transitions (Whittington et al., 1997b).]

2-site threshold stimulus

site 1

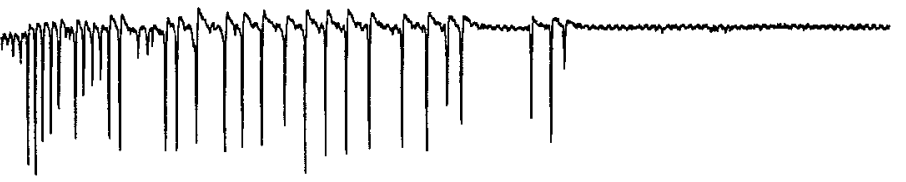

site 2

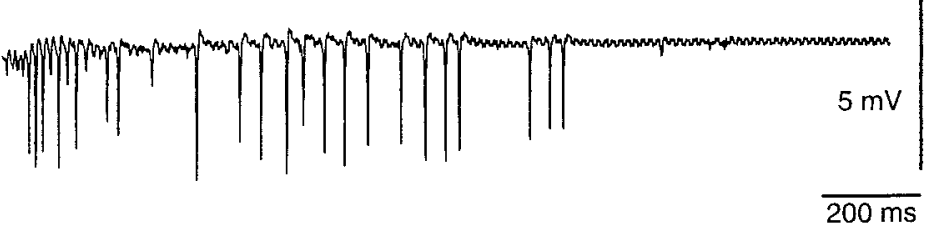

$\mathrm{mV}(\mathrm{SEM})$ at $0 \mathrm{~min}$, six EPSPs of amplitude $2.2 \pm 1.0 \mathrm{mV}$ at 4 $\mathrm{min}$, and nine EPSPs of amplitude $1.4 \pm 0.5 \mathrm{mV}$ at $8 \mathrm{~min}$. For the second interneuron, there were seven EPSPs of amplitude $3.6 \pm$ $0.4 \mathrm{mV}$ at $0 \mathrm{~min}$, eight EPSPs of amplitude $2.1 \pm 0.6 \mathrm{mV}$ at $4 \mathrm{~min}$, and six EPSPs of amplitude $1.7 \pm 0.6 \mathrm{mV}$ at $8 \mathrm{~min}$. In each case, the decline in mean amplitude between 0 and 8 min was statistically significant ( $p<0.05$, nonpaired $t$ test).

\section{DISCUSSION}

There are two main results in this paper. First, $\gamma$ - and $\beta$-frequency oscillations, induced by tetanic stimulation of the CA1 region in vitro, are synchronized by different cellular mechanisms. IPSPs are critical for shaping $\gamma$ [because GABA $_{\mathrm{A}}$ receptor blockade abolishes the oscillation (Whittington et al., 1995; Colling et al., 1998)], and EPSPs onto interneurons are necessary for long-range synchrony (Traub et al., 1996a,b; Whittington et al., 1997a), but EPSPs between pyramidal cells within CA1, so far

as we can tell, do not play an essential role in $\gamma$ oscillations. In contrast, EPSPs between CA1 pyramidal cells do appear to be critical for generating a synchronized $\beta$ rhythm, even within a local population of neurons, although such EPSPs may not be necessary for individual pyramidal cells to fire at $\beta$ frequency (Fig. 6).

Second, the contrasting cellular mechanisms of $\gamma$ and $\beta$ oscillations allow synaptic plasticity to regulate long-range synchrony of the two frequency ranges by different means.

To make sense of these results, we first briefly review the cellular mechanisms of $\gamma$ and $\beta$ (induced by tetanic stimulation in CA1), according to our present notions.

\section{Mechanisms of $\gamma$ oscillations, tetanically induced in CA1}

One can view the structure of $\gamma$ in three levels of complexity.

(1) Pharmacologically isolated networks of interneurons, when tonically excited, can produce locally synchronized $\gamma$ oscillations, 


\section{pyramidal cell}

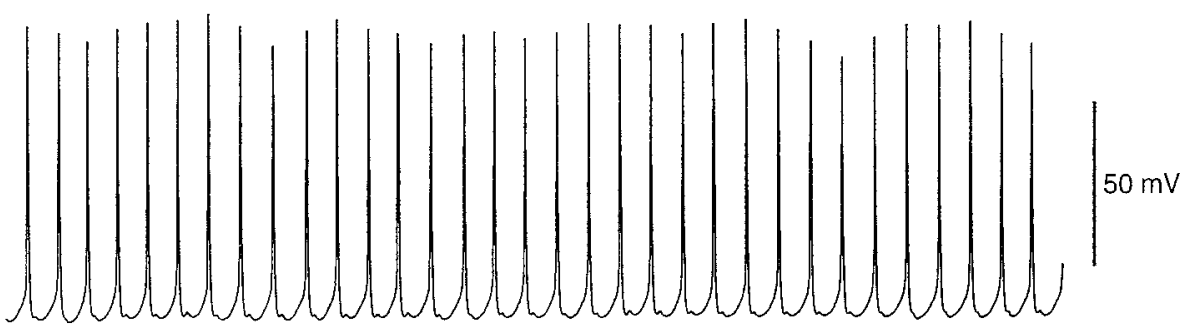

\section{pyramidal cell}

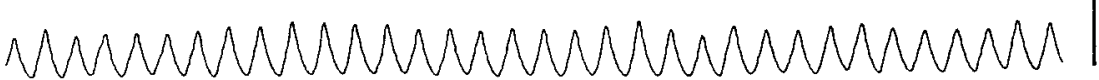

\section{basket cell}

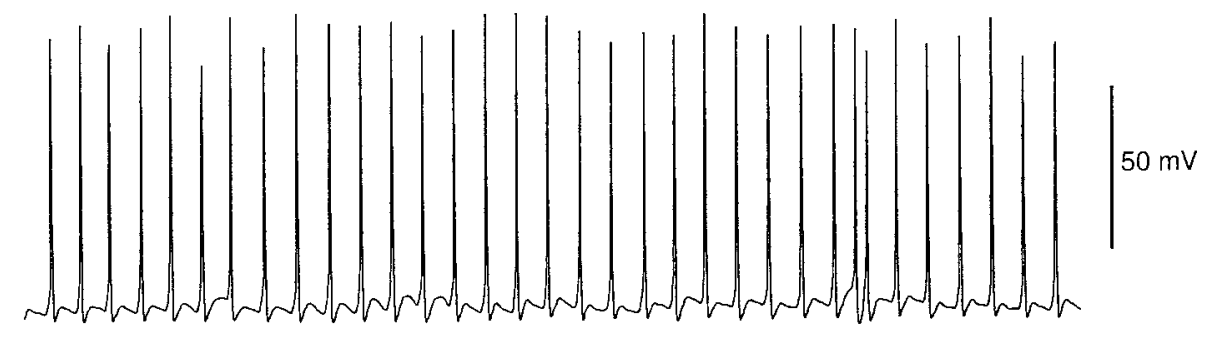

$100 \mathrm{~ms}$

\section{$B$}

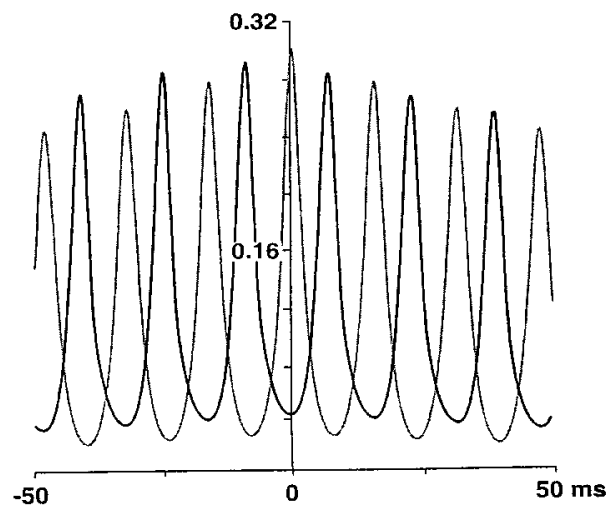

dependent on $\mathrm{i} \rightarrow \mathrm{i}$ synaptic interactions $\left(\mathrm{GABA}_{\mathrm{A}}\right.$ receptors), and with frequency dependent on "drive" to the interneurons and the parameters of the $\mathrm{i} \rightarrow \mathrm{i}$ IPSCs (Whittington et al., 1995; Traub et al., 1996b). This type of oscillation appears to be incapable of maintaining synchrony over distances more than $\sim 1$ mm (Whittington et al., 1997a).

(2) Local networks of pyramidal cells and interneurons can also generate locally synchronized $\gamma$ oscillations ["local" means "on a distance scale of about $400 \mu \mathrm{m}$ " (Colling et al., 1998)]. In this case, interneurons and pyramidal cells fire in phase, to within a couple of milliseconds, and both pyramidal cells and interneurons fire in singlets (Traub et al., 1996a; Whittington et al., 1997a). Oscillation frequency can be modified by driving currents to the pyramidal cells alone, at least in simulations, as well as by IPSC parameters (Traub et al., 1997; Whittington et al., 1998).
Figure 10. Blockade of long-range pyramidal cell $\rightarrow$ interneuron synaptic interactions prevents interneuron spike doublets, and hence two-site synchronization cannot occur (simulation). Network parameters were the same as for the $\gamma$ phase of Figure 4 (maximal $g_{\mathrm{K}(\mathrm{AHP})} 0.25 \times$ its standard value, unitary pyramidal/pyramidal EPSC $0.75 \times t \times e^{-\mathrm{t} / 2} \mathrm{nS}$ ), with this exception: for any pyramidal cell $\rightarrow$ interneuron connection that crosses the array midline in either direction, the corresponding unitary EPSC takes on one-tenth of its usual amplitude $\left(2.0 \times t \times e^{-t} \mathrm{nS}\right)$. As usual, we illustrate two pyramidal cells (at $x=5$, and a hyperpolarized one at $x=91$ ) and a basket cell $(x=5) . A$, Because the AMPA receptormediated input to interneurons is close to the input that would occur with single-site stimulation [Fig. 2 and Traub et al. (1996a,b)], interneurons do not fire doublets. $B$, As a consequence, the two sides of the array do not oscillate synchronously (cross-correlation peak at $5.6 \mathrm{msec}$ ). Autocorrelation and cross-correlation of e-cell average signals are shown.
(3) Distributed (i.e., on a spatial scale more than $\sim 1 \mathrm{~mm}$ ) networks of pyramidal cells and interneurons can also generate synchronized $\gamma$ oscillations. The interneurons (stratum pyramidale and stratum oriens) often fire in doublets, and the pyramidal cell spikes and the first spike of the interneuron doublet are nearly in phase. Pyramidal cell spikes and the first spike of the interneuron arise from tonic driving conductances to the respective cell types, with timing gated by IPSPs. Because both pyramidal cells and interneurons "see" the "same" IPSPs, it makes sense that the two cell types fire nearly in phase. The second spike in the interneuron doublet arises from the AMPA receptormediated synaptic input generated by the synchronized pyramidal cell spike. Experiments, simulation studies, and mathematical analysis suggest that interneuron doublet-firing is necessary for long-range synchrony under these conditions and is not an epi- 
A Control: 2-site threshold stimulation

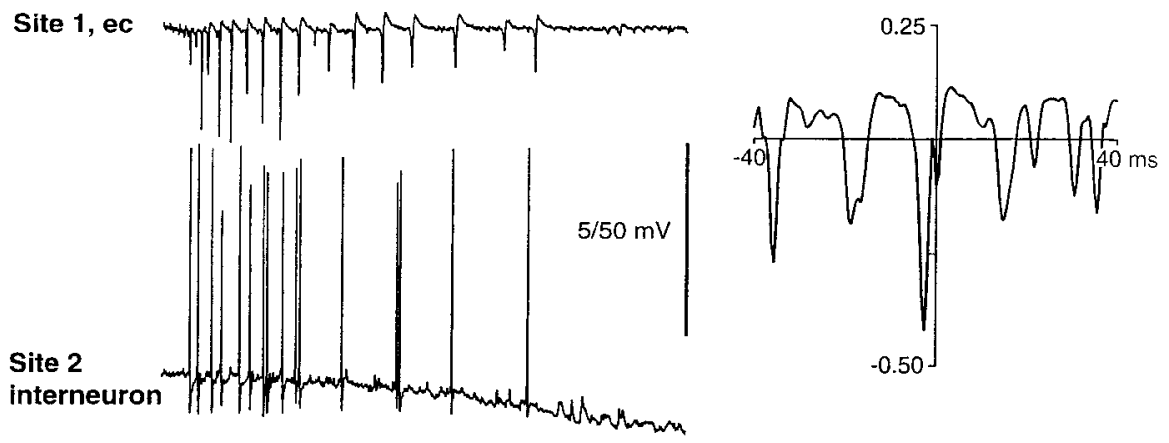

$B$ Conditioning: 1-site $2 x$ threshold stimulation

Figure 11. After twice-threshold stimulation-induced oscillations at one site, EPSPs are reduced in an interneuron at the other site, and subsequent two-site tetanic stimuli do not lead to interneuron doublets. All recordings are from the same slice, with an extracellular $(e c)$ recording electrode at site 1 and an intracellular recording of an interneuron at site 2 (same cell throughout the figure). Signals begin just after stimulus artifacts. $A, \gamma$ oscillation induced by two-site threshold stimulation. Note the interneuron doublets. Cross-correlation of the two signals produces a negative-going "peak" (because one signal is upgoing and the other downgoing) at -2 msec. $B$, The interneuron at site 2 was hyperpolarized to $-80 \mathrm{mV}$, near $\mathrm{GABA}_{\mathrm{A}}$ reversal potential, by passage of $-0.3 \mathrm{nA}$ current. Successive oscillations induced by twice-threshold stimulation of the opposite site lead to EPSPs in the interneuron that were of reduced amplitude and frequency. $C$, A subsequent two-site threshold tetanus-evoked oscillation is no longer associated with interneuron doublets. The variable phase relations of population spikes and action potentials leads to a disorganized appearance of the cross-correlation (right).

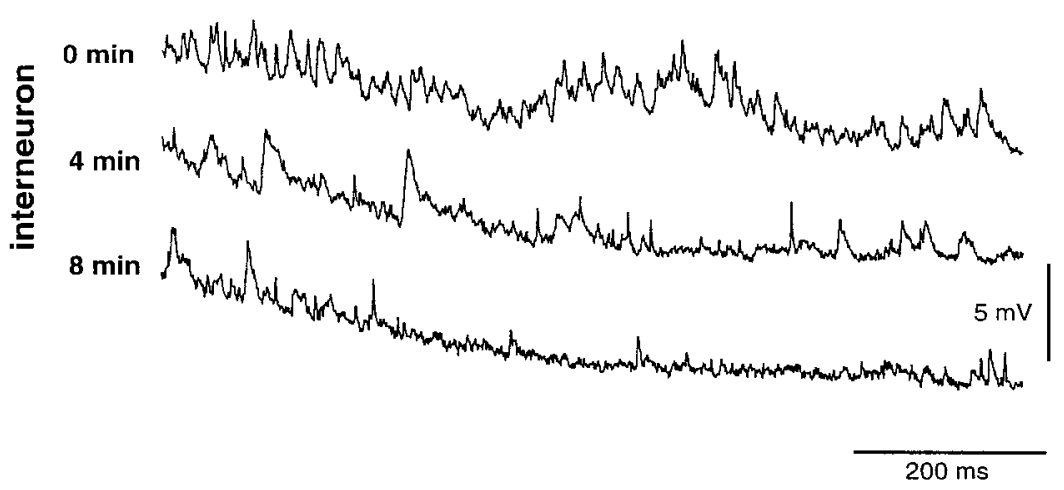

\section{Test: 2-site threshold stimulation}

Site 1, ec
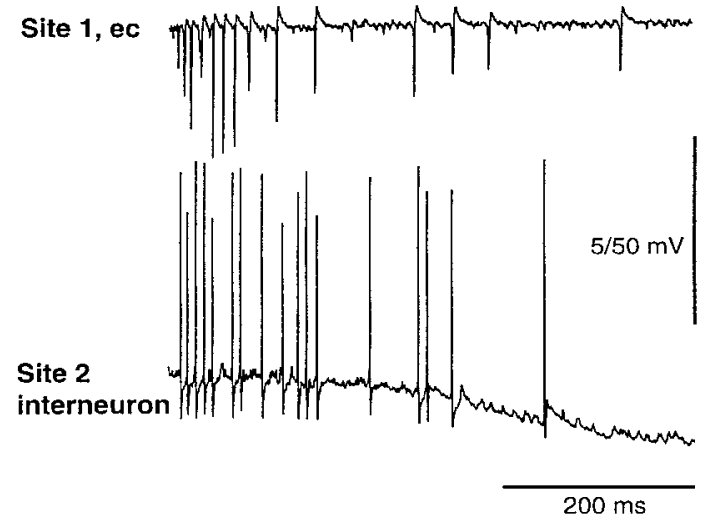

phenomenon (Whittington et al., 1997a; Ermentrout and Kopell, 1998).

The role of interneuron-interneuron IPSPs in cases (2) and (3), when pyramidal cells are firing in addition to interneurons, is not clear. The issue is difficult to examine experimentally, because one is required to block $\mathrm{GABA}_{\mathrm{A}}$ IPSCs selectively on interneurons and not on pyramidal cells, a problem that may require transgenic techniques. The mathematical model of Ermentrout and Kopell (1998) does not require interneuroninterneuron IPSPs.

Similarly, pyramidal-pyramidal EPSPs are not required in simulation models of CA1 $\gamma$ oscillations. Simulations indeed indicate that such EPSPs, if present at large enough amplitude, will lead to pyramidal cell doublets (rarely observed experimentally during $\gamma$ ) or to bursts (Traub et al., 1997; Whittington et al., 1997b). On the other hand, we do not have experimental data from paradigms in which EPSPs are selectively blocked on pyramidal cells and not on interneurons.

\section{Mechanisms of $\beta$ oscillations, tetanically induced in CA1}

After tetanic stimulation powerful enough to produce a $\gamma \rightarrow \beta$ switch, three experimental observations are salient. (1) Intracellular depolarizations are sustained during the $\beta$ phase, both in pyramidal cells (Whittington et al., 1997b) and in interneurons (present observations), and (2) pyramidal cell fast-spike AHPs, which virtually vanish during the $\gamma$ phase, recover before and 
during the $\beta$ phase (Whittington et al., 1997b). Presumably, slower $\mathrm{Ca}^{2+}$-dependent AHPs, which would also be blocked by metabotropic glutamate receptor activation (Charpak and Gähwiler, 1991), recover as well, before and during the $\beta$ phase, but we do not have direct experimental evidence for this. (3) AMPA receptor-mediated EPSPs develop in pyramidal cells before and during the $\beta$ phase.

By increasing the conductance of $\mathrm{Ca}^{2+}$-dependent AHPs alone, our present simulations indicate that observations (1) and (2) account for the slowing of individual pyramidal cell firings to $\beta$ frequency (Fig. 6). The reason is that the interneuron network continues to oscillate synchronously at $\gamma$ frequency, producing $\gamma$-frequency IPSPs in pyramidal cells, but the pyramidal cells, whose membranes are now more shunted, are unable to fire on each $\gamma$ wave. Because the pyramidal cells are not driven with identical tonic conductances, each pyramidal cell is free to develop its own pattern of wave-skipping, so that the $\beta$ oscillation will not synchronize. For this mechanism to operate in a stable manner, interneuron-interneuron IPSPs may possibly be required, but we have not examined this issue in detail. The recovery of $\mathrm{K}$ conductances with faster kinetics than the AHP conductance would be expected (1) to have either little effect on $\beta$ oscillations, if the kinetics is fast relative to the $40-100 \mathrm{msec}$ period of $\beta$ waves or (2) to reinforce the effects of recovery of the AHP conductance, by reducing the ability of pyramidal cells to fire on each $\gamma$ wave. It is possible that a time-dependent increase in membrane leak conductance could exert a functional effect similar to that of an increase in the slow AHP conductance.

On the other hand, when EPSPs between pyramidal cells of sufficient strength are added, then pyramidal cells interact with each other directly. The firing of some pyramidal cells on a particular $\gamma$ wave will tend to induce the firing of other pyramidal cells on that same $\gamma$ wave. Because AHPs remain large, however, each individual pyramidal cell still can fire only at $\beta$ frequency; it cannot, in general, fire on every $\gamma$ wave (Figs. 4, 5).

A by-product of this arrangement is that some pyramidal cells, being recurrently excited, will fire in doublets, whereas interneurons, being excited by pyramidal cell doublets, may sometimes fire in brief bursts (Figs. 4, 5).

An experimental prediction of this idea is that blockade of recurrent excitation, mediated by AMPA receptors, should prevent a synchronized $\beta$ oscillation, and this occurs (Fig. 7). Unfortunately, the drug used in this experiment, NBQX, also blocks AMPA receptors on interneurons. $\beta$ oscillations can occur, however, after joro toxin application (Fig. 3Bi), which blocks certain interneuron AMPA receptors. It therefore appears likely that NBQX prevents the occurrence of $\beta$ oscillations via a blockade of AMPA receptors at pyramidal cell $\rightarrow$ pyramidal cell synaptic connections.

\section{Strong tetanic stimulation, synaptic plasticity, and long-range synchronization}

\section{Cortical structures viewed as interconnected oscillating} neuronal ensembles

A commonly held view of the cortex might be characterized as follows. The computing units are single neurons, and information is stored, in a distributed manner, by modifying synaptic strengths (predominantly at pyramidal cell/pyramidal cell synapses) in a "Hebbian" manner, that is, dependent on the history of the correlations between presynaptic and postsynaptic activities.
The data on plasticity of $\gamma$ and $\beta$ oscillations are most readily interpreted within an alternative framework, the validity of which needs further investigation. Cortical structures, at least during certain states, consist of a collection of oscillating neuronal ensembles (Sompolinsky et al., 1990; Palm, 1982). These ensembles (which in our experiments would contain 1000 or 2000 neurons) can oscillate in synchrony or out of synchrony with each other, and information is stored in groups of synapses that interconnect the ensembles and determine whether synchronization is to occur in a particular band of frequencies.

\section{Long-range synchronization of $\beta$}

A two-site twice-threshold tetanus, given only one time, induces synchronized $\gamma$ and $\beta$ oscillations "acutely" (i.e., with onset tens of milliseconds after the stimulus); additionally, such a stimulus allows a later two-site threshold tetanus to induce synchronized $\gamma$ and $\beta$ oscillations (Fig. 9) (Whittington et al., 1997b). [Under control conditions, threshold-intensity tetani at two sites do not lead to synchronized $\beta$ oscillations (Fig. 9).] The long-lasting (tens of minutes, at least) inducibility of synchronized $\beta$ oscillations can be explained, according to our present results, by the fact that the EPSPs associated with the oscillation recur after threshold stimuli-induced oscillations, once these EPSPs have been induced by a twice-threshold stimulus (Whittington et al., 1997b), provided that the augmented EPSPs reflect functional recurrent connections between nearby as well as distant pyramidal cells.

\section{Long-range desynchronization of $\gamma$}

A twice-threshold tetanus delivered to one site rather than two has desynchronizing effects on two-site-stimulated $\gamma$ (threshold intensity stimuli), as opposed to the synchronizing effects of strong two-site tetanus on two-site-stimulated $\beta$ (Whittington et al., 1997b).

Because interneuron doublets are necessary for long-range synchrony of tetanically induced $\gamma$ oscillations, loss of interneuron doublets might explain $\gamma$ desynchronization. Interneuron doublets would disappear-so far as interneurons were concerned-if two-site stimulation were indistinguishable from one-site stimulation [Fig. 2 and Traub et al. (1996a,b)], and this situation would exist if single-site $2 \times \mathrm{T}$ stimulation were to cause depression of long-range pyramidal cell $\rightarrow$ interneuron connections. This scheme does indeed cause two-site $\gamma$ desynchronization in simulations (Fig. 10). Furthermore, experimental data indicate that one-site $2 \times \mathrm{T}$ tetanization leads to a loss of interneuron doublets (Fig. 11) when subsequent two-site threshold stimuli are delivered, stimuli that normally would cause interneuron doublets in at least some cells [Fig. 11 and Whittington et al. (1997a)].

Why might depression of long-range pyramidal cell $\rightarrow$ interneuron connections occur after a strong tetanus to a single site, say site 1? Following standard "Hebbian" ideas on LTP and LTD, let $\mathrm{e}_{1}$ and $\mathrm{e}_{2}$ denote pyramidal cells at sites 1 and 2, respectively, and $i_{1}$ and $i_{2}$ denote interneurons at sites 1 and 2 , respectively. $A$ strong tetanus to site 1 would be expected to cause intense firing of $e_{1}$ and $i_{1}$ but much less intense firing of $e_{2}$ and $i_{2}$. Under such conditions, both $\mathrm{e}_{1} \rightarrow \mathrm{i}_{2}$ and $\mathrm{e}_{2} \rightarrow \mathrm{i}_{1}$ would be expected to depress. Our data (Fig. 11) suggest that depression of $\mathrm{e}_{1} \rightarrow \mathrm{i}_{2}$ should occur, but we have no information about $\mathrm{e}_{2} \rightarrow \mathrm{i}_{1}$ or about $\mathrm{e}_{1} \rightarrow \mathrm{i}_{1}$. The experimental evidence also supports a secondary consequence of the presumed long-range synaptic depression: loss of interneuron doublets at the site opposite to the stimulated site. Again, we have no information concerning altered firing behavior in interneurons 
near to the stimulated site. With two-site stimulation, pyramidal cells and interneurons at both sites would be firing at high rates while also receiving synaptic excitation at high rates. One would not expect synaptic depression under these conditions.

In conclusion, $\gamma$ oscillations elicited by tetanic stimulation of CA1 in vitro are organized and synchronized by IPSPs and by AMPA receptors on interneurons. $\beta$ oscillations occur superimposed on $\gamma$ oscillations in interneuron networks: pyramidal cells do not fire on each $\gamma$ wave, and mutual EPSPs ensure that different pyramidal cells fire on the same $\gamma$ waves. The distinctive structure of the two sorts of oscillation provide different possible mechanisms for synaptic plasticity to modulate synchronization.

More speculatively, we might suggest the following. Suppose it is true that $\gamma$ oscillations are critical for perception, the detailed percept depending on which neurons oscillate in phase with each other. The occurrence of $\beta$ oscillations might, perhaps as a "flag," reflect the occurrence of a percept of particular novelty or significance, which at the cellular level would require sufficient activation of metabotropic receptors. Once such activation has occurred, the neuronal circuitry will have been modified (i.e., a memory will have been formed). The memory is "read" by the future expression of oscillation-synchronization, either in $\gamma$ or in $\beta$ frequencies or both. Note that what is here called " $\beta$ " is $10-25$ $\mathrm{Hz}$, a band that overlaps the $\alpha$ range of human EEG nomenclature. In human studies, with use of electroencephalographic and magnetoencephalographic data supplemented with other techniques that come along in future, the relations between $\gamma$ waves and immediately succeeding slower waves will prove interesting.

\section{REFERENCES}

Barth DS, MacDonald KD (1996) Thalamic modulation of highfrequency oscillating potentials in auditory cortex. Nature 383:78-81.

Buhl EH, Halasy K, Somogyi P (1994a) Diverse sources of hippocampal unitary inhibitory postsynaptic potentials and the number of synaptic release sites. Nature 368:823-828.

Buhl EH, Han Z-S, Lörinczi Z, Stezhka VV, Karnup SV, Somogyi P (1994b) Physiological properties of anatomically identified axo-axonic cells in the rat hippocampus. J Neurophysiol 71:1289-1307.

Charpak S, Gähwiler BH (1991) Glutamate mediates a slow synaptic response in hippocampal slice cultures. Proc R Soc Lond B Biol Sci 243:221-226.

Charpak S, Gähwiler BH, Do KQ, Knöpfel T (1990) Potassium conductances in hippocampal neurons blocked by excitatory amino acid transmitters. Nature 347:765-767.

Colling SB, Stanford IM, Traub RD, Jefferys JGR (1998) Limbic gamma rhythms. I. Phase-locked oscillations in hippocampal CA1 and subiculum. J Neurophysiol 80:155-161.

Deuchars J, Thomson AM (1996) CA1 pyramid-pyramid connections in rat hippocampus in vitro: dual intracellular recordings with biocytin filling. Neuroscience 74:1009-1018.

Ermentrout GB, Kopell N (1998) Fine structure of neural spiking and synchronization in the presence of conduction delays. Proc Natl Acad Sci USA 95:1259-1264

Geiger JRP, Melcher T, Koh D-S, Sakmann B, Seeburg PH, Jonas P, Monyer H (1995) Relative abundance of subunit mRNAs determines gating and $\mathrm{Ca}^{2+}$ permeability of AMPA receptors in principal neurons and interneurons in rat CNS. Neuron 15:193-204.

Glaze DG (1990) Drug effects. In: Current practice of clinical electroencephalography, ed 2 (Daly DD, Pedley TA, eds), pp 489-512. New York: Raven.

Gray CM (1994) Synchronous oscillations in neuronal systems: mechanisms and functions. J Comput Neurosci 1:11-38.

Guérineau NC, Bossu J-L, Gähwiler BH, Gerber U (1995) Activation of a nonselective cationic conductance by metabotropic glutamatergic and muscarinic agonists in CA3 pyramidal neurons of the rat hippocampus. J Neurosci 15:4395-4407.

Halasy K, Buhl EH, Lörinczi Z, Tamás G, Somogyi P (1996) Synaptic target selectivity and input of GABAergic basket and bistratified inter- neurons in the CA1 area of the rat hippocampus. Hippocampus 6:306-329.

Iino M, Koike M, Isa T, Ozawa S (1996) Voltage-dependent blockage of $\mathrm{Ca}^{2+}$-permeable AMPA receptors by joro spider toxin in cultured rat hippocampal neurones. J Physiol (Lond) 496:431-437.

König P, Engel AK, Singer W (1996) Integrator or coincidence detector? The role of the cortical neuron revisited. Trends Neurosci 19:130-137.

Leung LS (1992) Fast (beta) rhythms in the hippocampus: a review. Hippocampus 2:93-98.

McHugh TJ, Blum KI, Tsien JZ, Tonegawa S, Wilson MA (1996) Impaired hippocampal representation of space in CA1-specific NMDAR1 knockout mice. Cell 87:1339-1349.

Murthy VN, Fetz EE (1992) Coherent 25- to 35-Hz oscillations in the sensorimotor cortex of awake behaving monkeys. Proc Natl Acad Sci USA 89:5670-5674.

Palm G (1982) Neural assemblies. An alternative approach to artificial intelligence. Berlin: Springer.

Pantev C (1995) Evoked and induced gamma-band activity of the human cortex. Brain Topogr 7:321-330.

Pearce RA (1993) Physiological evidence for two distinct GABA $_{A}$ responses in rat hippocampus. Neuron 10:189-200.

Ribary U, Ioannides AA, Singh KD, Hasson R, Bolton JPR, Lado F, Mogilner A, Llinás R (1991) Magnetic field tomography of coherent thalamocortical $40-\mathrm{Hz}$ oscillations in humans. Proc Natl Acad Sci USA 88:11037-11041.

Roelfsema PR, Engel AK, König P, Singer W (1997) Visuomotor integration is associated with zero time-lag synchronization among cortical areas. Nature 385:157-161.

Salin PA, Prince DA (1996) Electrophysiological mapping of $\mathrm{GABA}_{\mathrm{A}}$ receptor-mediated inhibition in adult rat somatosensory cortex. J Neurophysiol 75:1589-1600.

Sik A, Penttonen M, Ylinen A, Buzsáki G (1995) Hippocampal CA1 interneurons: an in vivo intracellular labeling study. J Neurosci 15:6651-6665.

Singer W, Gray CM (1995) Visual feature integration and the temporal correlation hypothesis. Annu Rev Neurosci 18:555-586.

Sompolinsky H, Golomb D, Kleinfeld D (1990) Global processing of visual stimuli in a neural network of coupled oscillators. Proc Natl Acad Sci USA 87:7200-7204

Stanford IM, Traub RD, Jefferys JGR (1998) Limbic gamma rhythms. II. Synaptic and intrinsic mechanisms underlying spike doublets in oscillating subicular neurons. J Neurophysiol 80:162-171.

Steriade M, Amzica F (1996) Intracortical and corticothalamic coherency of fast spontaneous oscillations. Proc Natl Acad Sci USA 93:2533-2538.

Steriade M, Timofeev I, Dürmüller N, Grenier F (1998) Dynamic properties of corticothalamic neurons and local cortical interneurons generating fast rhythmic $(30-40 \mathrm{~Hz})$ spike bursts. J Neurophysiol 79:483-490.

Tamamaki N, Nojyo Y (1990) Disposition of the slab-like modules formed by axon branches originating from single CA1 pyramidal neurons in the rat hippocampus. J Comp Neurol 291:509-519.

Traub RD, Miles R (1991) Neuronal networks of the hippocampus. Cambridge, UK: Cambridge UP.

Traub RD, Miles R (1995) Pyramidal cell-to-inhibitory cell spike transduction explicable by active dendritic conductances in inhibitory cell. J Comput Neurosci 2:291-298.

Traub RD, Wong RKS, Miles R, Michelson H (1991) A model of a CA3 hippocampal pyramidal neuron incorporating voltage-clamp data on intrinsic conductances. J Neurophysiol 66:635-650.

Traub RD, Miles R, Jefferys JGR (1993) Synaptic and intrinsic conductances shape picrotoxin-induced synchronized after-discharges in the guinea-pig hippocampal slice. J Physiol (Lond) 461:525-547.

Traub RD, Jefferys JGR, Miles R, Whittington MA, Tóth K (1994) A branching dendritic model of a rodent CA3 pyramidal neurone. J Physiol (Lond) 481:79-95.

Traub RD, Colling SB, Jefferys JGR (1995) Cellular mechanisms of 4-aminopyridine-induced synchronized after-discharges in the rat hippocampal slice. J Physiol (Lond) 489:127-140.

Traub RD, Whittington MA, Colling SB, Buzsáki GB, Jefferys JGR (1996a) Analysis of gamma rhythms in the rat hippocampus in vitro and in vivo. J Physiol (Lond) 492:471-484.

Traub RD, Whittington MA, Stanford IM, Jefferys JGR (1996b) A 
mechanism for generation of long-range synchronous fast oscillations in the cortex. Nature 383:621-624.

Traub RD, Jefferys JGR, Whittington MA (1997) Simulation of gamma rhythms in networks of interneurons and pyramidal cells. J Comput Neurosci 4:141-150.

Wang X-J, Buzsáki G (1996) Gamma oscillation by synaptic inhibition in a hippocampal interneuronal network model. J Neurosci 16:6402-6413.

White JA, Chow CC, Ritt J, Soto-Treviño C, Kopell N (1998) Synchronization and oscillatory dynamics in heterogeneous, mutually inhibited neurons. J Comput Neurosci 5:5-16.

Whittington MA, Traub RD, Jefferys JGR (1995) Synchronized oscilla- tions in interneuron networks driven by metabotropic glutamate receptor activation. Nature 373:612-615.

Whittington MA, Stanford IM, Colling SB, Jefferys JGR, Traub RD (1997a) Spatiotemporal patterns of $\gamma$ frequency oscillations tetanically induced in the rat hippocampal slice. J Physiol (Lond) 502:591-607.

Whittington MA, Traub RD, Faulkner HJ, Stanford IM, Jefferys JGR (1997b) Recurrent excitatory postsynaptic potentials induced by synchronized fast cortical oscillations. Proc Natl Acad Sci USA 94:12198-12203.

Whittington MA, Traub RD, Faulkner HJ, Jefferys JGR, Chettiar K (1998) Morphine disrupts long-range synchrony of gamma oscillations in hippocampal slices. Proc Natl Acad Sci USA 95:5807-5811. 